\title{
LILIANA REVOLLEDO
}

ESTUDO DA RESPOSTA IMUNE, DA COLONIZAÇÃO E INVASÃO POR Salmonella enterica subsp enterica sorotipo Typhimurium $\mathrm{Nal}^{r}$ EM FRANGOS DE CORTE, TRATADOS COM GLUCANO, PROBIÓTICOS E PRODUTOS DE EXCLUSÃO COMPETITIVA

São Paulo 2005 


\section{LILIANA REVOLLEDO}

Estudo da resposta imune, da colonização e invasão por Salmonella enterica subsp enterica sorotipo Typhimurium $\mathrm{Nal}^{\mathrm{r}}$ em frangos de corte, tratados com glucano, probióticos e produtos de exclusão competitiva

Tese apresentada para ao Programa de PósGraduação em Patología Experimental e Comparada da Faculdade de Medicina Veterinária e Zootecnia da Universidade de São Paulo para a obtenção do título de Doutor em Ciências

Departamento:

Patologia

Área de Concentração:

Patologia Experimental e Comparada

Orientador:

Prof. Dr. Antonio José Piantino Ferreira

\section{São Paulo}


Autorizo a reprodução parcial ou total desta obra, para fins acadêmicos, desde que citada a fonte.

\section{DADOS INTERNACIONAIS DE CATALOGAÇÃO-NA-PUBLICAÇÃO}

(Biblioteca da Faculdade de Medicina Veterinária e Zootecnia da Universidade de São Paulo)

T.1601

FMVZ
Revolledo, Liliana

Estudo da resposta imune, da colonização e invasão por Salmonella enterica subsp enterica sorotipo Typhimurium $\mathrm{Nal}^{\mathrm{r}}$ em frangos de corte, tratados com glucano, probióticos e produtos de exclusão competitiva / Liliana Revolledo. - São Paulo: L. Revolledo, 2005.

$121 \mathrm{f}$ : : il.

Tese (doutorado) - Universidade de São Paulo. Faculdade de Medicina Veterinária e Zootecnia. Departamento de Patologia, 2005.

Programa de Pós-graduação: Patologia Experimental e Comparada.

Área de concentração: Patologia Experimental e Comparada.

Orientador: Prof. Dr. Antonio José Piantino Ferreira.

1. Salmonella. 2. Imunidade intestinal. 4. Pobióticos. 5. Exclusão competitiva. I. Título.
3. Glucanos. 


\section{UNIVERSIDADE DE SÃO PAULO \\ Faculdade de Medicina Veterinária e Zootecnia \\ Cidade Universitária "Armando de Salles Oliveira” \\ Comissão Bioética \\ CERTIFICADO}

Certificamos que o Projeto intitulado “Determinação da resistência à colonização por Salmonella enterica subsp enterica sorotipo Kedougou (NCTC 1273), detecção de SigA intestinal e $\operatorname{IgG}$ sérica em aves tratadas com exclusão competitiva, probióticos e glucanos", Protocolo $n^{0} 12 / 2001$, sob a responsabilidade do Prof. Dr. Antonio José Piantino Ferreira, está de acordo com os princípios éticos de experimentação animal da Comissão de Bioética da Faculdade de Medicina Veterinária e Zootecnia da Universidade de São Paulo e foi aprovado em reunião de 30/01/2002.

(We certify that the Research "Determination of resistance to colonization of Salmonella enterica subsp enterica serotype Kedougou (NCTC 12173), detection of intestinal SigA and serum IgG, in chicks treated with competitive exclusion products, probiotics and glucans" protocol number 12/2001, under the responsability of Prof. Dr. Antonio José Piantino Ferreira, agree with Ethical Principles in Animal Research adopted by Bioethic Commision of the Faculty of Veterinary Medicine and Zootechny of, University of São Paulo and was approved in 01/30/2002 meeting.)

São Paulo, 30 de janeiro de 2002

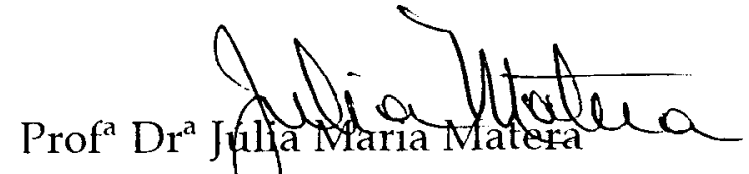

Presidente da Comissão de Bioética

FMVZ/USP 


\section{FOLHA DE AVALIAÇÃO}

Nome: REVOLLEDO, Liliana

Título: Estudo da resposta imune, da colonização e invasão por Salmonella enterica subsp enterica sorotipo Typhimurium Nal ${ }^{r}$ em frangos de corte, tratados com glucano, probióticos e produtos de exclusão competitiva

Tese apresentada para ao Programa de PósGraduação em Patología Experimental e Comparada da Faculdade de Medicina Veterinária e Zootecnia da Universidade de São Paulo para a obtenção do título de Doutor em Ciências

Data:

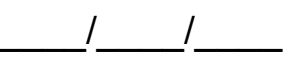

Banca Examinadora

Prof. Dr. Instituição:

Assinatura: Julgamento:

Prof. Dr. Instituição:

Assinatura: Julgamento:

Prof. Dr. Instituição:

Assinatura: Julgamento:

Prof. Dr. Instituição:

Assinatura: Julgamento:

Prof. Dr. Instituição:

Assinatura: Julgamento: 
A la memoria de mi padre

A mi madre, por su apoyo permanente A mis amigos por la amistad sin condiciones 


\section{AGRADECIMENTOS}

Ao Prof. Dr. Antonio José Piantino Ferreira, pela amizade, pela confiança e o apoio permanente;

À Prof. Dra. Claudete Serrano Astolfi Ferreira, pela amizade, ajuda constante e as sugestões sempre oportunas;

Aos meus amigos e colegas de Laboratório, Laura, Márcia, Jorge, Amarilis, Debora, Karina, Terezinha, Eliana, Marcos, Marcelo, Antonio Carlos, pela amizade, apoio, e convivência;

A Kátia, pelo apoio, amizade e paciência, permanentes;

A Bia, Norha pela amizade e apoio, durante a execução dos experimentos;

A Jam pela amizade, auxílio e sugestões na revisão e formatação do texto;

A Patrícia pela amizade e auxílio indispensável na formatação e revisão das referências bibliográficas;

A Maria José Aparecida Louro e Paulo Sérgio de Souza, pelo auxílio sempre indispensável;

Ao Instituto e Matemática da USP pelo auxílio para os cálculos dos parâmetros logísticos;

Ao CNPq e à Faculdade de Medicina Veterinária e Zootecnia da Universidade de São Paulo, pela oportunidade. 


\section{RESUMO}

REVOLLEDO, L. Estudo da resposta imune, da colonização e invasão por Salmonella enterica subsp enterica sorotipo Typhimurium $\mathrm{Nal}^{\mathrm{r}}$ em frangos de corte, tratados com glucano, probióticos e produtos de exclusão competitiva. [Study of immune response, colonization, and invasion by Salmonella enterica subsp. enterica serotype Typhimurium (1796NR) Nal in broiler chickens, treated with glucans, probiotics, and competitive exclusion products]. 2005. $121 \mathrm{f}$. Tese (Doutorado em Ciências) - Faculdade de Medicina Veterinária e Zootecnia, Universidade de São Paulo, São Paulo, 2005.

O efeito de sete tratamentos, contendo $\beta$-glucano, um probiótico experimental, e um produto de exclusão competitiva assim como suas associações, foram avaliados frente a um desafio com Salmonella Typhimurium $\mathrm{Nal}^{r}$ e na resposta imune, em frangos de corte. Dois experimentos foram realizados; o primeiro experimento apresentou seis tratamentos que consistiram de: a) produto de exclusão competitiva $(E C)$; b) $E C$ + probiótico experimental (LEB); c) EC + betaglucano (G); d) $E C+L E B+G$; e) controle negativo e f) controle positivo. O segundo experimento, foi delineado com nove tratamentos que consistiram em: a) EC; b) LEB; c) G; d) $E C+L E B$; e) $E C+G$; f) $E C+L E B+G$; g) $L E B+G$; h) controle negativo e i) controle positivo. Experimento 1: no dia 0 do experimento as aves foram tratadas com $0,1 \mathrm{~mL}$ de EC por inoculação no inglúvio. No dia 1 do experimento as aves foram desafiadas com $10^{7} \mathrm{CFU} / \mathrm{mL}$ de Salmonella Typhimurium (1796NR) Nal ${ }^{\mathrm{r}}$. Durante o período de 1 ao $6 \mathrm{dia}$, as aves foram tratadas com o tratamento apropriado, e sacrificadas aos 7 dias de idade. Experimento 2: no dia 0 do experimento as aves foram tratadas com 0,1mL de EC por inoculação no inglúvio. Durante 28 dias as aves foram tratadas com o tratamento apropriado. Nos dias 1, 9, 16 e 23 do experimento as aves foram desafiadas com $10^{7} \mathrm{UFC} / \mathrm{mL}$ de Salmonella Typhimurium (1796NR) Nal ${ }^{\mathrm{r}}$, e sacrificadas uma semana após cada desafio. Nos dois experimentos, cecos, fígado e baço foram removidos assepticamente e examinados para Salmonellae; e foram 
colhidas amostras de soro e fluido intestinal, para se avaliar as concentrações de $\lg$ e $\lg A$ totais. Os dados foram analisados por análise de variança de uma via, e as médias comparadas pelo teste de Duncan. Os tratamentos EC+LEB+G e LEB+G mostraram uma inibição significativa $(p<0,05)$ de invasão dos órgãos por Salmonella Typhimurium (1796NR) Nal' ${ }^{r}$ com altos níveis de proteção. No segundo experimento, a colonização cecal foi reduzida somente após a segunda semana de tratamento. Os níveis de IgG não foram significativos no soro ou fluido intestinal, mas a concentração de $\lg A$ foi significativamente $(p<0,05)$ alta no soro e fluido intestinal, quando comparada com a do controle negativo. Estes resultados sugerem que os tratamentos associados usando produto de EC, probióticos e betaglucano são mais eficazes no controle de Salmonella, do que preparações individuais; estimulando a produção de $\lg$ A sistêmica e de mucosas. Outros estudos complementares são necessários para se determinar os mecanismos pelos quais as interações destas substâncias poderiam regular a resposta imune inata.

Palavras-chave: Salmonella, imunidade intestinal, glucanos, probióticos, exclusão competitiva. 


\begin{abstract}
REVOLLEDO, L. Study of immune response, colonization, and invasion by Salmonella enterica subsp. enterica serotype Typhimurium (1796NR) Nal ${ }^{r}$, in broiler chickens, treated with glucans, probiotics, and competitive exclusion products. [Estudo da resposta imune, da colonização e invasão por Salmonella enterica subsp enterica sorotipo Typhimurium $\mathrm{Nal}^{r}$ em frangos de corte, tratados com glucano, probióticos e produtos de exclusão competitiva]. 2005. $121 \mathrm{f}$. Tese (Doutorado em Ciências) - Faculdade de Medicina Veterinária e Zootecnia, Universidade de São Paulo, São Paulo, 2005.
\end{abstract}

The effects of seven treatments, containing $\beta$-glucan, experimental probiotic, competitive exclusion products and their associations were evaluated, on a Salmonella Typhimurium Nal ${ }^{r}$ challenge and assessment of the immune response, in broiler chickens. Two sets of trials were performed; the first trial was arranged with six treatments. Treatments in the first set consisted of a) commercial competitive exclusion (EC), b) EC + experimental probiotic (LEB), c) EC + betaglucan (G), d) $E C+L E B+G$, e) negative control, and e) positive control. The second one, was designed with nine treatments consisted of a) EC, b) LEB, c) G, d) EC+LEB, e) $E C+G, f) E C+L E B+G, g) L E B+G, h$ ) negative control, and i) positive control. Trial 1: on day 0 birds were administered $0,1 \mathrm{~mL}$ of the $\mathrm{EC}$ treatment by oral gavage. On day 1, birds were challenged with $10^{7} \mathrm{CFU} / \mathrm{mL}$ of Salmonella Typhimurium (1796NR) Nal ${ }^{\mathrm{r}}$. During 1 to 6 days, birds were administered of appropriate treatment, and were sacrificed at 7 days of age. Trial 2: on day 0 birds were administered $0,1 \mathrm{~mL}$ of the EC treatment by oral gavage. During 28 days, birds were administered of appropriate treatment. On day $1,9,16$ and 23 birds were challenged with $10^{7} \mathrm{CFU} / \mathrm{mL}$ of Salmonella Typhimurium (1796NR) $\mathrm{Nal}^{\mathrm{r}}$, and were sacrificed one week after challenge. In two sets of trials, ceca, liver and spleen were aseptically removed and examined for salmonellae; and were taken serum and intestinal fluid samples, in 
order to evaluate total antibody concentrations of $\lg G$ and $\lg A$. Data were analyzed by one-way analysis of variance, and means compared by Duncan's test. Treatments $E C+L E B+G$ and $L E B+G$ resulted in a significant inhibition $(p<0,05)$ in Salmonella Typhimurium (1796NR) Nal ${ }^{r}$ organ invasion offering a higher level of protection. In the second set of trial, colonization was reduced after the second week of treatment. $\lg G$ was no significantly in serum and intestinal fluid samples, but IgA was found significantly $(p<0,05)$ higher in serum and intestinal fluid samples, when compared to control ones. These results suggest that associated treatment using EC products, probiotics and betaglucans are more effective in Salmonella control, than individual preparations; stimulating the systemic and mucosal immune response mediated by $\lg \mathrm{A}$. Further research is necessary to determine the mechanisms by which the interaction of these substances could regulate avian innate immune response.

Key words: Salmonella, immunity, glucans, probiotics, competitive exclusion. 


\section{LISTA DE FIGURAS}

Figura 1 - Concentrações médias de lgG $(\mathrm{ng} / \mathrm{mL})$ em soros ...................... 57

Figura 2 - Concentrações médias de lgG $(\mathrm{ng} / \mathrm{mL})$ em conteúdo

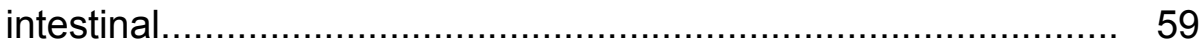

Figura 3 - Concentrações médias de $\operatorname{lgA}(\mathrm{ng} / \mathrm{mL})$ em soros........................ 61

Figura 4 - Concentrações médias de $\operatorname{lgA}(\mathrm{ng} / \mathrm{mL})$ em conteúdo

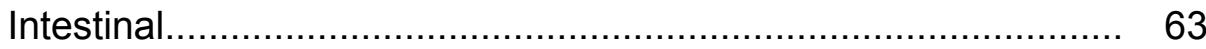

Figura 5 - Comparação das concentrações de $\operatorname{lgA}(\mathrm{ng} / \mathrm{mL})$

no soro durante todo o periodo do experimento........................... 64

Figura 6 - Comparação das concentrações de $\lg A(n g / m L)$

no conteúdo intestinal durante todo o periodo do

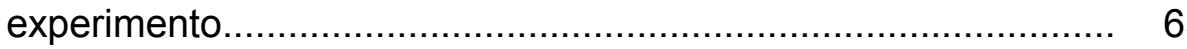




\section{LISTA DE TABELAS}

Tabela 1 - Tratamentos e número de aves

Tabela 2a - Delineamento experimental dos grupos de Tratamento com Exclusão competitiva e suas associações(EC)

Tabela 2b- Delineamento experimental dos grupos de Tratamento durante todo o periodo do experimento.

Tabela 3 - Inibidores de proteases utilizados

Tabela 4 - Média de $\log _{10}$ UFC Salmonella/g em amostras de aves tratadas com produtos de EC e suas associações

Tabela 5 - Fator de infectividade (IF) e Fator de proteção (PF), em aves tratadas com produtos de EC e suas associações, na primeira semana de idade.

Tabela 6 - Valores médios referênciais de concentração de $\lg G$ e $\lg A$ $(\mathrm{ng} / \mathrm{mL})$ no dia 0 do experimento.

Tabela 7 - Concentração média de lgG $(\mathrm{ng} / \mathrm{mL})$ em soros, durante todo o periodo do experimento

Tabela 8 - Concentração média de lgG $(\mathrm{ng} / \mathrm{mL})$ no conteúdo intestinal, durante todo o periodo do experimento.

Tabela 9 - Concentração média de $\operatorname{lgA}(\mathrm{ng} / \mathrm{mL})$ em soros, durante todo o periodo do experimento 
Tabela 10 - Concentração média de $\operatorname{lgA}(\mathrm{ng} / \mathrm{mL})$ no conteúdo intestinal, durante todo o periodo do experimento................................ 62

Tabela 11 - Média de $\log _{10}$ UFC Salmonella/g em amostras de aves, na segunda semana de idade.................................................. 66

Tabela 12 - Média de $\log _{10}$ UFC Salmonella/g em amostras de aves, na terceira semana de idade.

Tabela 13 - Média de $\log _{10}$ UFC Salmonella/g em amostras de aves, na quarta semana de idade. 
$1 \quad$ INTRODUÇÃO

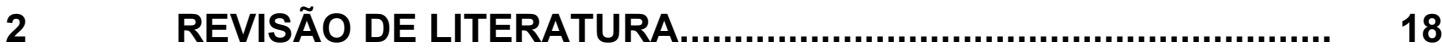

$2.1 \quad$ Salmonela e saúde pública............................................................. 18

2.2 Colonização do trato gastrointestinal e invasão dos órgãos por Salmonela...................................................................... 20

$2.3 \quad$ Exclusão competitiva............................................................. 23

$2.4 \quad$ Probióticos......................................................................... 25

$2.5 \quad$ Glucanos como imunomoduladores........................................... 29

2.6 Imunidade intestinal nas aves.................................................. 30

$3 \quad$ MATERIAL E MÉTODOS........................................................... 34

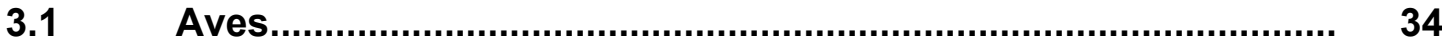

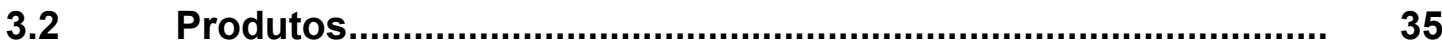

3.2.1 Exclusão competitiva............................................................

3.2.2 Probiótico ............................................................................. 36

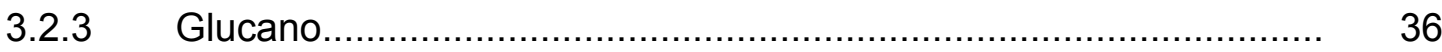

3.3 Preparo do probiótico experimental............................................... 36

3.3.1 Obtenção das culturas bacterianas.......................................... 36

3.3.2 Concentração das culturas bacterianas...................................... 37

3.3.3 Mistura das culturas bacterianas e obtenção da semente.......... 37

3.3.4 Concentração da semente do pool bacteriano.............................. 38

3.3.5 Preparação do produto final....................................................... 38 
3.4. Infecção experimental................................................................. 38

3.4.1 Amostra bacteriana.................................................................... 38

3.4.2 Determinação da concentração bacteriana para desafio das

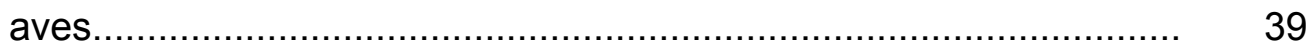

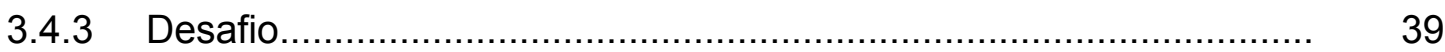

3.5 Obtenção das amostras............................................................. 42

3.5.1 Amostras de soro................................................................... 42

3.5.2 Amostras de conteúdo intestinal............................................... 42

3.5.3 Reisolamento de Salmonella Typhimurium de amostras de cecos e

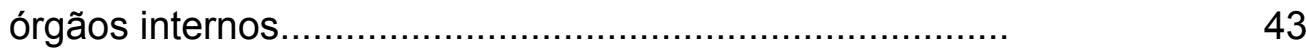

3.5.4 Delineamento experimental......................................................... 44

3.6 Detecção e quantificação de $\lg$ e $\lg A$ no soro e conteúdo 45 intestinal.

3.7 Eficácia dos tratamentos............................................................ 46

3.8 Análise estatística.......................................................................... 47

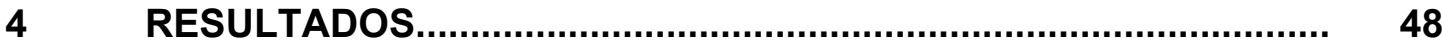

$5 \quad$ DISCUSSÃO

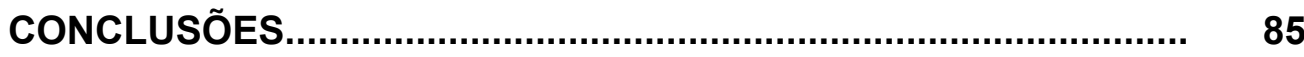

REFERÊNCIAS BIBLIOGRÁFICAS.............................................. 86

APÊNDICES ............................................................................. 101 


\section{INTRODUÇÃO}

Salmonella constitui um gênero bacteriano difundido mundialmente e com importância econômica e na saúde pública (UZZAU et al., 2000). Esta bactéria é reconhecida mundialmente como a maior causadora de diarréia em humanos (NAUTA et al., 2000) e os produtos avícolas como uns dos maiores veículadores da infecção por Salmonella spp. (BRYAN; DOYLE, 1995).

Em aves, há basicamente dois tipos de infecção por Salmonella: a sistêmica e a entérica. Infecções sistêmicas com Salmonella Pullorum ou Salmonella Gallinarum representaram durante muitos anos um sério problema na industria avícola (BORLAND, 1975). Estes agentes são considerados espécieespecíficos (UZZAU et al., 2000), foram controlados e erradicados em muitos países, através programas nacionais de controle, como resultado da globalização e a abertura dos mercados.

Salmonella Typhimurium e Salmonella Enteritidis são espécies ubiqüas, não tifóides que podem afetar qualquer espécie, inclusive as aves (PADRON, 1990; RAMPLING et al., 1989; SUZUKI, 1994) e o homem (ETHELBERG et al., 2004; MAZUREK et al., 2004; PERSSON; JENDTEG, 1992; ROBERTS; SOCKETT, 1994). As aves podem ser portadoras assintomáticas através da colonização entérica. A susceptibilidade diminui com a idade e aves adultas podem converter-se em portadoras da bactéria (NURMI; RANTALA, 1973). 
A prevenção de salmonelas constituiu-se em preocupação prioritária dos profissionais envolvidos no processo de criação e exploração de aves. Esta área da sanidade avícola recebeu nestes últimos anos uma maior relevância, pela sua importância na saúde pública. Os programas de controle são complexos e existem uma série de fontes de contaminação (BAILEY et al. 2000) incluindo as aves, o alimento, os roedores, aves silvestres, insetos, transportes, meio ambiente e o homem. Para um controle eficaz, é necessário o uso de estratégias de intervenção em todas estas fontes mencionadas.

Dentre as ações dirigidas especificamente às aves, para o controle da salmonelose nas criações comerciais, estão incluidas os produtos de exclusão competitiva (MEAD, 2000), probióticos (FERREIRA et al., 1998), ácidos orgânicos ou inorgânicos (HINTON; HINTON, 1988), vacinas (METHNER et al., 1999), imunoadjuvantes (ACEVEDO et al., 2001; MORRIS et al., 1999; MUIR, 1998), antibióticos (MANNING et al., 1994; MOORE et al., 1946), programas de monitoramento, entre outras. Todas estas medidas assim como o estabelecimento da biossegurança nas integrações avícolas, converteram-se em ferramentas imprescindíveis na criação comercial de aves e uma exigência para atender as demandas no comércio internacional de produtos avícolas.

Nos últimos anos, devido ao desenvolvimento de pesquisas, demonstrouse que outras substâncias denominadas glucanos, isolados da parede celular de fungos, agem como estimuladores do sistema imune e exercem um efeito benéfico (BOHN; BEMILLER, 1995; DI LUZIO, 1983; STONE; CLARKE, 1992). O uso desta substância demonstrou atividade imunomoduladora em camundongos 
(HASHIMOTO, 1991) e nas aves estimula a resposta imune humoral e a resposta de linfócitos T inespecíficos (ACEVEDO et al., 2001).

Neste sentido, este experimento foi delineado para propor um programa eficaz de controle de salmonelas paratíficas em frangos de corte, através de uma alternativa de tratamento inócua para as aves e sem a presença de resíduos nos produtos avícolas. Como parte do delineamento foram administrados produtos de exclusão competitiva, probióticos e glucano, separadamente ou em associação, adicionados posteriormente à ração e fornecidos aos frangos, tendo como objetivos:

a) Avaliar os efeitos dos tratamentos sobre a resposta imune nas aves, mediante a quantificação dos níveis de $\lg A$ e $\lg G$ no soro e conteúdo intestinal.

b) Verificar a eficácia do produto de exclusão competitiva e suas associações, em aves desafiadas com uma amostra virulenta de Salmonella Typhimurium $\mathrm{Nal}^{r}$, através do protocolo descrito por Mead et al (1989).

c) Determinar os efeitos dos tratamentos na colonização cecal em aves desafiadas com uma amostra virulenta de Salmonella Typhimurium Nal' .

d) Avaliar os efeitos dos tratamentos na invasão dos órgãos em aves desafiadas com uma amostra virulenta de Salmonella Typhimurium Nal' . 


\section{REVISÃO DE LITERATURA}

\subsection{SALMONELA E SAÚDE PÚBLICA}

Embora, existam mais de 2300 sorotipos de Salmonella, apenas um pequeno número de sorotipos tipicamente produzem doenças similar ao tifo em animais adultos em número restrito de espécies hospedeiras. Estas incluem: Salmonella Typhi e Salmonella Paratyphi em humanos, Salmonella Cholerae-suis em suinos, Salmonella Dublin em bovinos, e Salmonella Gallinarum em aves (TURNER et al., 1998). Salmonella Typhimurium e Salmonella Enteritidis são uma exceção, desde que são capazes de colonizar o trato gastrointestinal de aves e causar infecção tifóide em camundongos.

Existe um predomínio destes dois sorotipos causando toxi-infecções em humanos (NAUTA et al., 2000; SILLIKER, 1980) e contaminação nas aves (BRYAN; DOYLE, 1995). Salmonella enterica subsp enterica sorotipo Enteritidis é responsável por muitos surtos em humanos (ISAACS et al, 2005; PERSSON; JENDTEG, 1992; RAMPLING et al., 1989; ROBERTS; SOCKETS, 1994; TANSEL et al., 2003) mas surtos com Salmonella enterica subsp. enterica sorotipo Typhimurium também são frequentes (BOCCIA et al., 2004; ETHELBERG et al., 2004; MAZUREK et al., 2004).

A dificuldade de se estabelecer medidas de controle está relacionada às inúmeras fontes potenciais de contaminação por Salmonella na indústria avícola. Salmonella spp. pode transmitir-se horizontal ou verticalmente (HUMPHREY et 
al., 1988), sendo que diferentes linhagens de reprodutores e poedeiras estão envolvidas na transmissão da doença, e frequentemente não apresentam sinais clínicos.

Os frangos de corte e as poedeiras comercias não são exceção, tendo sido demonstrada a prevalência de Salmonella nas aves e seus produtos (BOONMAR et al., 1998; CORRAL et al., 1983; HANG'OMBE et al., 1999; POPPE et al. 1991; SIMMONS, 1968). Existem poucas informações sobre a epidemiologia da infecção em galinhas reprodutoras pesadas e frangos de corte quando se compara com aquelas obtidas em poedeiras. Porém, alguns estudos têm demonstrado que a presença de Salmonella em frangos de corte produz atraso no crescimento quando infectados verticalmente (LISTER, 1988).

Dentre as possibilidades de contaminação em frangos com Salmonella, além da transmissão vertical, a mais importante é a utilização de alimento contaminado (ALLRED et al., 1967; ZINDEL; BENNET, 1968), a qual pode ocorrer por ratos (BAINS; MACKENZIE, 1974) e outros fatores. Embora, muitos ingredientes possam estar contaminados por Salmonella (DAWKINS; ROBERTSON, 1967; ISA et al., 1983), os considerados potencialmente perigosos e de maior risco como veículos de infecção são as farinhas de origem animal (BERCHIERI, 1989; BIRCHOFF, 1969; SILVA et al., 1973; STOTT et al., 1975; VAUGHN et al., 1974).

Existe também a possibilidade que Salmonella contamine a ração durante o processamento (GIORGI et al., 1971; HACKING et al., 1978). A capacidade 
desta para permanecer viável no ambiente contribui para a sua persistência nas aves. Foi demonstrado que esta bactéria pode permanecer viável por 18 meses em uma ração armazenada entre 20 a $25^{\circ} \mathrm{C}$ (SMYSER et al., 1963). Comprovouse também a sua presença em amostras de galpões de frangos de corte, alimentos e meio ambiente (POPPE et al., 1991), dessa forma, conhecendo-se os resultados da contaminação por Salmonella nos galpões pode-se definir o perfil de contaminação das carcaças e o grau de contaminação das granjas (CHAMBERS et al., 1998).

Esta bactéria pode ser transferida do conteúdo intestinal para a carcaça durante o processo industrial (KVENBERG; ARCHER, 1987; MC GARR et al., 1980; RAMPLING et al., 1989). Há muitos anos, sabe-se que a contaminação das carcaças é um achado comum (BOONMAR et al., 1998; CORRAL et al., 1983; HANG'OMBE et al., 1999; SIMMONS, 1968), podendo atingir a $72 \%$ nas amostras de carne de frango.

A presença de Salmonella spp. em carcaças de aves está relacionada com a colonização intestinal por esta bactéria, que é maior durante os primeiros dias de vida das aves. Salmonella Enteritidis, além de colonizar o intestino das aves como muitos outros sorotipos, invade órgãos internos como folículos ovarianos, oviduto, fígado, pâncreas, baço e vesícula biliar.

\subsection{COLONIZAÇÃO DO TRATO GASTROINTESTINAL E INVASÃO DOS ÓRGÃOS POR SALMONELA}

Um primeiro passo para a colonização pela bactéria é a associação física entre ela e o epitélio (FULLER, 1973; SMITH; HALLS, 1968). A ligação das 
células microbianas através de adesinas superficiais é um fenômeno fundamental nas infecções microbianas e na patogenia (KELLY; YOUNSON, 2000). O epitélio intestinal representa uma interface entre o meio ambiente externo e o interno dentro do hospedeiro, considerando-se a maior via de entrada de patógenos (UZZAU et al., 2000).

Há pouca informação disponível em relação aos mecanismo pelos quais Salmonella coloniza o trato digestivo dos frangos. Um deles, é a capacidade de multiplicar-se no conteúdo intestinal, migrar através da mucosa, aderir e invadir o epitélio. A adesão física foi sugerida como um mecanismo de colonização intestinal (SOEJARDI et al., 1982) e há evidência de que as fímbrias promovem a colonização de Salmonella infantis no intestino (BARROW et al., 1988), Salmonella Enteritidis (HORNS et al., 1996) e Salmonella Typhimurium (LOCKMAN; CURTIS, 1992).

Alguns sorotipos de Salmonella colonizam mais eficientemente o trato digestivo de frangos que outros (AABO et al., 2002; BARROW et al., 1988; SMITH; TUCKER, 1980). Salmonella Montevideo persiste no intestino de frangos e é excretada com as fezes por um longo período quando comparada com Salmonella Typhimurium. Na ausência de doença clínica, Salmonella Pullorum, Salmonella Gallinarum e Salmonella Cholerae suis colonizam muito pouco o trato alimentar de frangos, provavelmente porque estas bactérias tenham condições nutricionais específicas (TURNER et al., 1998). No entanto, é necessário considerar a possibilidade que diferentes sorotipos de Salmonella possam usar mecanismos alternativos para a colonização, pois alguns genes são ativados (TURNER et al., 1998). 
Salmonella não pertence à microbiota normal das aves, mas é capaz de colonizar os intestinos de frangos jovens e persistir durante todo o período de criação. Esta bactéria se localiza preferencialmente nas tonsilas cecais, na primeira metade do intestino delgado, no proventrículo e moela (FANELLI et al.,1971).

Existem inúmeros fatores que afetam a susceptibilidade dos frangos à colonização por Salmonella:

a) idade : frangos jovens são mais suscetíveis à colonização que frangos adultos (BAILEY, 1987);

b) sobrevivência na passagem através da barreira gástrica: a colonização é dependente da cepa de Salmonella e da dose de desafio (LAFONT et al., 1983);

c) estado de saúde e doenças intercorrentes (QIN, et al. 1995);

d) competição efetiva com outras bactérias (BARROW et al., 1987);

e) estresse do meio ambiente: agentes estressantes aumentam a susceptibilidade à colonização (WEINACK et al, 1985);

f) genética: a herança tem um importante papel na susceptibilidade de diferentes linhagens de frangos à colonização por Salmonella (BERTHELOT et al., 1998; BUMSTEAD et al., 1993; LAMONT, 1998).

g) aditivos: aditivos e outros produtos alteram a microbiota normal, aumentando a susceptibilidade à colonização. (McHAN, et al.,1989; OYOFO et al., 1989). 
Por outro lado, alguns fagotipos, por exemplo o fagotipo 4 de Salmonella Enteritidis é mais invasivo em aves jovens que outras cepas classificadas nos fagotipos 7, 8 e 13a (HINTON et al., 1990).

\subsection{EXCLUSÃO COMPETITIVA}

A importância da microbiota normal no controle de enteropatógenos tem sido demonstrada em animais que mostraram colonização precoce da microbiota intestinal nativa, a qual previne o estabelecimento de salmonelas paratifóides em pintinhos (BOLDER et al., 1992; LLOYD et al., 1977; NURMI et al., 1973; SOEJARDI et al., 1981; SNOEYENBOS et al., 1979).

Volterra (1928) foi o primeiro em sugerir que a co-existência de duas ou mais espécies está limitada, e que a localização em um mesmo espaço é impossível. Exclusão competitiva, pelo nome, implica a prevenção da entrada de um agente dentro de um ambiente pré-colonizado. Dessa forma, a bactéria é capaz de estabelecer-se e manter-se nesse ambiente, compete ou produz substâncias inibidoras para a bactéria invasora (BAILEY, 1988). Os mecanismos deste efeito protetor ainda não foram elucidados, porém tem sido proposto que a microbiota nativa exerça uma exclusão competitiva, diminuindo as bactérias contaminantes no trato intestinal de frangos. Parece que este mecanismo tem sido amplamente aceito (SEUNA, 1979; SOEJARDI et al., 1981; STAVRIC, 1987).

Vários fatores atuam na exclusão, mas considera-se esta interação importante na obtenção do efeito final. A importância da microbiota intestinal foi observada em uma infecção experimental com Salmonella spp. em pintinhos, onde se reconheceu que a resistência natural às infecções por Salmonella spp. 
se desenvolvia com o estabelecimento de uma microbiota intestinal semelhante à microbiota de um animal adulto (MILNER; SHAFFER, 1952).

Exclusão competitiva é um fenômeno que foi descrito pela primeira vez em 1973 por Nurmi e Rantala, após um surto por Salmonella Infantis ocorrido na Finlândia. É reconhecido como um método de colonização precoce do intestino, onde os microrganismos são excluídos devido à competição exercida pela microbiota pré-instalada. $\mathrm{O}$ conceito pode ser resumido como segue: a) pintos de um dia infectam-se com uma única célula de Salmonella spp.; b) aves adultas são resistentes à infecção pela existência da microbiota nativa do intestino; c) a introdução da microbiota de uma ave adulta em um pinto de um dia acelera o processo de amadurecimento da microbiota e aumenta a resistência dos pintinhos à colonização por Salmonella spp. (PIVNICK et al. 1981)

Outros compostos têm sido testados, em relação à colonização cecal por Salmonella, por exemplo o efeito dos carboidratos (BAILEY et al., 1991; CORRIER et al., 1990; HOLLISTER et al., 1995; OYOFO et al.,1989; ZIPRIN et al., 1990); sendo que alguns deles demonstraram melhores resultados que outros, na inibição da colonização (CORRIER et al., 1994; FUKATA et al., 1999). Outros produtos, como os ácidos graxos voláteis, também podem ter efeitos inibitórios especialmente quando dissociados em pH 6.0 (MEAD, 2000).

Atualmente, a exclusão competitiva em frangos de corte vêm sendo utilizada, para reduzir a contaminação por Salmonella Enteritidis nas carcaças processadas, reduzindo a exposição dos consumidores a toxi-infecções alimentares (BAILEY, 2000). 
A maioria dos produtos de exclusão competitiva utilizam microbiota intestinal de aves adultas saudáveis. O controle enteropatogênico pode ser: a) químico: existem grupos bacterianos que através de uma rede de fímbrias bloqueiam os locais de ligação de alguns patógenos entéricos, e outras têm a capacidade de diminuir o pH pela produção de ácidos orgânicos inibindo os patógenos entéricos; b) biológico: devido aos diferentes gêneros bacterianos presentes na EC, que colonizam e se desenvolvem, produz-se um ambiente de exclusão quase permanente, que confere à mucosa uma identidade estrutural à composição bacteriana; c) físico: os produtos de exclusão competitiva criam um sistema de integridade espacial, que impede que os patógenos intestinais encontrem um lugar para se estabelecer; d) bioquímicos: muitos microrganismos produzem substâncias inibidoras que permitem manter um grupo de bactérias em um determinado lugar espacial e nutricional, no ambiente intestinal. Demostrouse que três mecanismos apresentavam um importante papel na prevenção da colonização entérica de pintinhos pré-tratados com produtos de exclusão competitiva (EC): a) os microrganismos que compõem a cultura de EC estabelecem uma flora entérica antes da exposição à Salmonella spp.; b) os microrganismos de EC competem com Salmonella spp. por nutrientes essenciais, e c) os microrganismos de EC, produzem concentrações de ácidos graxos voláteis que diminuem $\mathrm{o} \mathrm{pH}$ e são bacteriostáticos para Salmonella spp. (SCANLAN, 1997).

\subsection{PROBIÓTICOS}

O termo probiótico foi introduzido por Lilly e Stilwell (1965) para descrever substâncias produzidas por um organismo que estimulam o crescimento de 
outros. A definição mais comum utilizada é a de Fuller (1993) que denomina probióticos àqueles microrganismos que acrescentados ao alimento afetam beneficamente o balanço microbiano intestinal; sendo então o efeito primário sua influência benéfica no ecosistema intestinal, produzindo proteção contra as infecções gastrointestinais e doenças inflamatórias do intestino.

Alguns prováveis mecanismos de ação têm sido descritos, entre eles os principais são os seguintes:

a) produção de substâncias antimicrobianas (REID et al., 1988)

A produção de substâncias inibidoras por um tipo de microrganismo que age em outros tipos bacterianos (antagonismo), é frequentemente citada como um mecanismo pelo qual as comunidades de microrganismos são reguladas. Muitas destas substâncias são classificadas como peptídeos, proteínas ou complexos carboidratos-proteínas. Estes compostos são produzidos por muitas espécies bacterianas, incluindo lactobacilos e geralmente são denominados bacteriocinas. Por exemplo, a lactacina F é uma bacteriocina produzida pelo Lactobacillus johnsonii VPI 11088, sendo a mais estudada bioquímica e geneticamente (BRASSART; SCHIFFRIN, 1997).

Estas substâncias inibidoras são geralmente solúveis em água, atuam em baixas concentrações e agem suprimindo espécies de bactérias potencialmente negativas para o meio ambiente intestinal. As bactérias patogênicas são, deste modo inibidas permitindo uma maior eficiência na assimilação de nutrientes o que favorece o ganho de peso. A produção de ácidos graxos voláteis pela microbiota, é responsável pelo controle da colonização do intestino por bactérias como Escherichia coli. 
b) imunoestimulação de células residentes (BENGMARK, 2000; PERDIGON et al., 1990)

Probióticos administrados oralmente contendo lactobacilos estimulam a capacidade imunológica contra muitas espécies bacterianas. A estimulação da função dos macrófagos, especialmente a fagocitose encontra-se aumentada. Este efeito é produzido provavelmente pela absorção de antígenos solúveis ou pela translocação de lactobacilos da parede intestinal para a corrente sangüinea. A capacidade dos macrófagos de fagocitar, matar e eliminar microrganismos que invadem o hospedeiro é extremamente importante para a manutenção da saúde. Muitos produtos químicos, farmacêuticos e especialmente antibióticos, inibem ou reduzem a função dos macrófagos na sua capacidade de produzir e secretar citocinas e desenvolver atividade bactericida. Geralmente, as bactérias lácticas vivas ou mortas, embora não sejam todas, são conhecidas porque estimulam a função dos macrófagos e induzem a produção de citocinas.

c) exclusão competitiva (OUWENHAND et al., 1999)

A competição por sítios de adesão é um dos mecanismos propostos para demonstrar a ação dos probióticos. Demonstrou-se que muitos patógenos intestinais são capazes de aderir-se à parede intestinal e colonizar, sendo este um pré-requisito à produção da doença; alguns probióticos têm sido selecionados pela sua capacidade de aderir aos tecidos e competir com as bactérias patogênicas por esse lugar. Pode-se concluir que o local de adesão ocupado pela bactéria não patogênica, impede a colonização pelas bactérias patogênicas. 
d) competição pelos nutrientes (OUWEHAND et al., 1999)

O intestino é uma fonte rica em nutrientes, cuja composição determina a dinâmica da microbiota.

O uso de probióticos como promotores de crescimento em animais está aumentando, com resultados positivos na melhora do ganho de peso e na conversão alimentar (KABIR et al., 2004). Tem sido utilizados diferentes microrganismos tais como: varias espécies de Lactobacillus, Saccharomyces cerevisiae, Aspergillus oryzae, Enterococcus faecium, Bifidobacterium bifidum e outros. Nas poedeiras tem sido demonstrado além do ganho de peso e melhora na conversão alimentar, o aumento da resistência a doenças e na produção de ovos.

Os probióticos apresentam efeitos benéficos para o hospedeiro (FERREIRA et al., 1998). Entre os mais importantes podem ser mencionados os seguintes: a) influência positiva na microbiota intestinal: favorecem o crescimento de bactérias da mcrobiota normal do intestino, mantendo o equilibrio do meio; b) prevenção de infecções do trato intestinal: interferem por diferentes mecanismos com as bactérias patogênicas, previnindo a adesão e colonização do trato intestinal; c) estimulação da imunidade local: os probióticos estimulam a produção de IgA secretora no intestino, a qual previne a colonização de bactérias patogênicas, além disso estimulam a imunidade sistêmica pela estimulação da produção de IgG; d) redução de reações inflamatórias: devido à sua capacidade de proteger o intestino de agentes invasores, reduz de maneira significativa as enterites; e) regulação da motilidade 
intestinal: pelo balanço entre solutos e líquidos dentro do intestino, regulam a motilidade intestinal, favorecendo a absorção de nutrientes.

\subsection{GLUCANOS COMO IMUNOMODULADORES}

Há alguns anos identificou-se que algumas substâncias biológicas podiam influenciar e aumentar os mecanismos inespecíficos de defesa nos animais. Estas substâncias foram denominadas de imunoestimulantes, embora sejam produzidos por diferentes fontes. Dentre estas substâncias, as paredes celulares de leveduras que incluem glucanos e mananoligossacarídeos, estão entre aquelas naturais (ENGSTAD; ROBERTSEN, 1993).

Uma fonte de mananoligossacarídeos e glucanos é a parede celular das leveduras, que na sua composição têm $30 \%$ de manana, $30 \%$ de glucano e $12,5 \%$ de proteína, entre os componentes mais importantes. Glucano é um polissacarídeo composto de glicose com ligações $\beta$ 1,6 e $\beta$ 1,3 (ENSLEY et al., 1994). Glucano isolado da parede de Saccharomyces cerevisiae, é um polissacarídeo com efeitos benéficos que atualmente está recebendo atenção especial (KARAOGLU; DURDAG, 2005) em diversos campos da medicina humana e veterinária.

É amplamente conhecido que produtos como a aveia, fungos unicelulares ou pluricelulares possam estimular os movimentos intestinais. Os $\beta$-glucanos são os maiores componentes destes produtos, e aumentam o número e função de linfócitos intraepiteliais (TSUKADA et al., 2003)

Os efeitos benéficos dos glucanos, foram demonstrados em diferentes espécies, em aquacultura foi descrito um aumento da imunidade específica na 
carpa indiana rohu (Labeo rohita Hamilton) (SAHOO; MUKHERJEE, 2001). Foi demonstrado também, que estes produtos potencializavamm a imunidade antimicrobiana em camundongos (SHERWOOD et al., 2001). Os $\beta$-glucanos podem ser responsáveis pelo aumento da imunidade intestinal no trato digestivo (HASHIMOTO et al., 1991; TSUKADA et al., 2003).

A atividade dos $\beta$-glucanos como imunoestimulantes tem sido avaliada em diferentes espécies de mamíferos (KATAOKA et al., 2002) e aves (ACEVEDO et al., 2001a; ACEVEDO et al, 2001b; BENDA et al., 1989). Mostrou-se sua ação na estimulação da resposta inespecífica após a administração por via oral, tornandose uma importante alternativa quando é necessário estimular a imunidade mediada por células.

Os $\beta$-glucanos foram utilizados como um aditivo abiótico para regular a resposta imune em aves. A sua eficácia na redução da invasão dos órgãos por Salmonella Enteritidis em aves foi demonstrada por Lowry et al. (2005)

\subsection{IMUNIDADE INTESTINAL NAS AVES}

A maioria dos agentes invadem os animais através das mucosas. Têm sido amplamente demonstrado que a presença de anticorpos protetores nas superfícies mucosas, protegem 0 animal da entrada de microrganismos (OUWENHAND et al.,1999). Porém, muitos imuno adjuvantes têm sido estudados sem conseguir efetivamente estimular a resposta imune local, principalmente no intestino (MUIR, 1998).

Muitos mecanismos relacionados ao desenvolvimento da imunidade intestinal das aves já foram revisados por Muir em 1998. O sistema imune das 
mucosas é composto de tecido linfóide associado às mucosas (MALT), incluindo a passagem nasal, órgãos bronquiais, trato genital e o tecido linfóide associado ao intestino (GALT). O GALT é um tecido exposto a antígenos do alimento, microbiota normal do intestino e patógenos entéricos. Nas aves, este tecido está presente em toda a extensão do trato intestinal, porém a maior área é constituída pelas placas de Peyer e tonsilas cecais. O repertório de linfócitos presentes compreendem de 45 a $55 \%$ de células B e $35 \%$ de células T, envolvidas na produção de anticorpos e funções de imunidade mediada por células (BEFUS et al., 1980). As placas de Peyer são os maiores elementos do tecido linfóide associado ao intestino (GALT) conhecidos por regular a produção de IgA secretora (YUN et al., 2000). Por isso, a utilização de agentes capazes de estimular a resposta local, como adjuvantes orais é uma das alternativas para a prevenção de colonização de microrganismos patogênicos.

O mecanismo de defesa associado à mucosa intestinal é mediado pela IgA secretora (SigA) (MUIR et al. 2000). Nas mucosas, o sistema imune pode agir por três mecanismos: a) "exclusão imune", um termo utilizado para definir uma proteção de superfície não inflamatória em colaboração com os fatores de defesa inatos; b) regulação imune, com participação de células apresentadoras de antígeno (APC), ativação de linfócitos $\mathrm{T}$ e $\mathrm{B}$, liberação de citocinas e c) eliminação imune, que envolve a estimulação de mediadores e células de defesa inata, assim como, a produção de imunoglobulinas (BRANDTZAEG et al., 1999). Pela interação de fatores inatos de defesa, os anticorpos presentes na mucosa intestinal, proporcionam um efeito de exclusão onde a ligação entre a SlgA e o antígeno, interfere com a adesão na superfície e na colonização das bactérias patogênicas (WILLIAMS; GIBBONS, 1972). 
As aves jovens têm poucas células produtoras de imunoglobulinas no intestino, aumentando sua concentração como resposta à colonização do trato gastrointestinal (PARRY et al. , 1977) como resultado da atividade mitogênica dos lipopolissacarídeos bacterianos (POWELL, 1987). Isto pode também contribuir para o estabelecimento de infecção por Salmonella spp., devido à colonização lenta pela microbiota (NURMI; RANTALA,1973; NURMI et al., 1992). A microbiota normal é importante para a estimulação precoce e o amadurecimento do componente celular no sistema imune intestinal. Estas bactérias nativas modulam a resposta imune pelo aumento ou diminuição de mediadores secretados pelas células imunocompetentes associadas com 0 intestino e pela estimulação de linfócitos $T$ auxiliares e supressores (BERG, 1985; DE SIMONE, 1986; KLUPSCH, 1985; WEIR e BLACKWELL, 1983).

O material antigênico recebido pelo GALT é apresentado diretamente às células do sistema imune pelos enterócitos (MAYER; SHLIEN, 1987). Alternativamente, os antígenos podem mover-se através ou entre os enterócitos (MADARA, 1997) ou pelas áreas especializadas do epitélio associado ao folículo, chamadas células M (JEURISSEN et al., 1999; KERNEIS et al. 1997), que nas aves estão infiltradas com linfócitos e localizadas nas placas de Peyer e divertículo de Meckel (MUIR, 1998).

Os limitados estudos envolvendo a captação de antígenos pelo GALT das aves não tem sido conclusivos (MUIR, 2000). A manipulação da microbiota intestinal, usando produtos de exclusão competitiva, probióticos e imunoadjuvantes é uma alternativa potencial para estimular a resposta imune nas aves tratadas, especialmente relacionado à ativação da SigA. 
Desde que a mucosa intestinal é modulada pela interação da microbiota com o sistema imune, é provável que mudanças durante o crescimento afetem este microambiente (CUNNINGHAM-RUNDLES, 2004). Em aves o período pós nascimento apresenta maior importância imunológica, porque a ave está imediatamente exposta a antígenos. Além disso, a população de células B no GALT começa apenas 4 dias após o nascimento e aumenta durante as primeiras duas semanas (BAR-SHIRA et al., 2003).

A imunidade gerada nas mucosas é um fator importante no sistema imune, pois pode refletir na imunidade, em outros tecidos ou sistemas fisiológicos do organismo, contra agentes infecciosos. A resposta imune intestinal contra Salmonella spp. abrange uma série de interações complexas, que incluem as citocinas, os leucócitos, células epiteliais e outro fatores presentes no GALT (BLOOM; BOEDEKER, 1996; FUKUTOME et al., 2001). As citocinas apresentam um papel crítico na indução e expressão da resposta de IgA nas superfícies mucosas (HUSBAND, 2002). 


\section{MATERIAL E MÉTODOS}

\subsection{AVES}

Foram utilizadas aves de corte da linhagem Ross, machos, de um dia de idade, divididas em nove grupos (Tabela 1), cada grupo foi composto de quatro repetições, de 10 aves cada uma.

As aves foram recebidas no primeiro dia de vida e alojadas aleatoriamente em boxes de aproximadamente $1,70 \mathrm{~m}^{2}$ no Centro Experimental de Patologia Aviária da FMVZ-USP, em São Paulo. Os boxes, para alojamento das aves, foram previamente lavados e desinfectados, e testados após a desinfecção para a presença de Salmonella spp. através de swabs de arrastro.

As aves foram mantidas sob aquecimento elétrico durante a primeira semana de vida, entre $30-34^{\circ} \mathrm{C}$, e posteriormente à temperatura ambiente. Foram alimentadas com ração comercial sem aditivos medicamentosos e sem anticoccidianos (Apêndice A) e água ad libitum, durante quatro semanas.

Os tratamentos foram distribuídos da seguinte forma:

a) EC: Exclusão competitiva no dia de chegada das aves nos tratamentos correspondentes (T1, T4, T5 E T6).

b) LEB: Probiótico, administrado durante todo o período de criação das aves dependendo dos grupos tratados (T2, T4, T6 e T7).

c) G: Glucano, administrado durante todo o período de criação das aves, segundo descrito em cada grupo (T3, T5, T6 e T7).

As combinações de produtos seguiram os mesmo padrões de administração que os grupos individuais. 
d) Grupo controle negativo: grupo mantido separadamente, não tratado e não desafiado (T8).

e) Grupo controle positivo: grupo mantido separadamente, não tratado e desafiado como o esquema descrito nas Tabelas $2 a$ e $2 b$.

Tabela 1- Tratamentos e número de aves.

\begin{tabular}{lc}
\hline Tratamento & $\mathbf{N}^{\circ}$ de aves \\
\hline T1-Exclusão competitiva (EC) & 40 \\
T2-Probiótico (LEB) & 40 \\
T3-Glucano (G) & 40 \\
T4-EC+LEB & 40 \\
T5-EC+G & 40 \\
T6-EC+LEB+G & 40 \\
T7-LEB+G & 40 \\
T8-Controle negativo & 40 \\
T9-Controle positivo & 40 \\
\hline TOTAL & $\mathbf{3 6 0}$ \\
\hline
\end{tabular}

\subsection{PRODUTOS}

\subsubsection{Exclusão competitiva (EC)}

Foi utilizado um produto comercial, que consistiu em um liofilizado parcial de microrganismos derivados de microbiota intestinal normal de frangos adultos saudáveis, livres de patógenos específicos (SPF). O produto continha por cada grama, $100 \mathrm{mg}$ de bactérias liofilizadas e $900 \mathrm{mg}$ de 
maltodextrina. O produto era um pó fino, branco, solúvel em água, densidade $550 \mathrm{~g} / \mathrm{L}, \mathrm{pH} 6.8$.

O produto foi misturado com água de bebida e administrado nas aves com uma cânula de aço inoxidável, na proporção de $0,1 \mathrm{~mL}$ por ave.

\subsubsection{Probiótico (LEB)}

Foram utilizadas culturas bacterianas obtidas no Laboratório de Patologia Aviária da FMVZ-USP (LEME, 1998; PAÇO, 2001), composto de espécies de enterococos, lactobacilos e bifidobactérias (Apêndice B).

O produto foi utilizado na concentração aproximada de $1,6 \times 10^{11} \mathrm{UFC} / \mathrm{g}$ de ração.

\subsubsection{Glucano (G)}

Produto comercial não puro (Goldcell-Biorigin) ${ }^{1}$, foi adicionado á ração, na proporção de 1000 gramas por tonelada (Apêndice C). No tratamento só com glucano o produto foi administrado na mesma proporção por todo o período de criação das aves.

\subsection{PREPARO DO PROBIÓTICO}

\subsubsection{Obtenção das culturas bacterianas}

Cada amostra foi cultivada individualmente. Para o cultivo da amostras foram utilizados os meios de cultura seletivos: para lactobacilos caldo MRS; para bifidobactéria caldo seletivo (ATLAS, 1997) e para enterococos triptose soja (Apêndice D).

\footnotetext{
${ }^{1}$ Goldcell-Biorigin, é obtido a partir da parede celular de Saccharomyces cerevisiae.
} 
Para as culturas de lactobacilos foram utilizados frascos contendo $250 \mathrm{~mL}$ de caldo MRS para cada espécie cultivada e para os enterococos frascos contendo $500 \mathrm{~mL}$ de caldo triptose-soja, ambos cultivados a $37^{\circ} \mathrm{C}$ por 24 horas.

Bifidobacterium bifidum, foi cultivado em 1 litro de meio seletivo e a incubação foi realizada a $37^{\circ} \mathrm{C}$ por 36 horas em sistema de anaerobiose ${ }^{2}$.

\subsubsection{Concentração das culturas bacterianas}

As culturas bacterianas foram concentradas individualmente por centrifugação a $9000 \mathrm{~g}$ por 10 minutos a $4^{\circ} \mathrm{C}$. O sobrenadante foi desprezado e o "pellet" de cada tubo foi diluído em $2 \mathrm{~mL}$ de PBS estéril $(0,1 \mathrm{M}, \mathrm{pH} 7,4)$. As bactérias foram cultivadas individualmente, em seguida foram centrifugadas e agrupadas de acordo com a espécie.

\subsubsection{Mistura das culturas bacterianas e obtenção da semente}

Após serem misturadas, as amostras de lactobacilos e de enterococos, foram cultivadas separadamente em frascos contendo um litro de meio de cultura a $37^{\circ} \mathrm{C}$ por 24 horas. Após o crescimento dos grupos, as amostras seguiram o mesmo método de concentração descrito no item 3.3.2.

Cada pellet foi diluído em $2 \mathrm{~mL}$ de PBS $(0,1 \mathrm{M} \mathrm{pH} 7,4)$.

Preparou-se dois litros de meio de cultura para Bifidobacterium contendo $5 \%$ de Meio $199^{3}$ (Apêndice E), dividido em frascos de um litro.

\footnotetext{
${ }^{2}$ Probac do Brasil

${ }^{3}$ Cultilab
} 
Neste meio, semeou-se uma parte de lactobacilos, 3 partes de enterococos e 9 partes de bifidobactérias, sendo realizado cultivo tanto em aerobiose como em anaerobiose. O cultivo em aerobiose ocorreu em um período de 24 horas a $37^{\circ} \mathrm{C}$ e o realizado em anaerobiose na mesma temperatura por um período de 36 horas.

\subsubsection{Concentração da semente de pool bacteriano}

Após 24 horas para o cultivo em aerobiose e 36 horas para o cultivo em anaerobiose, o crescimento bacteriano foi concentrado individualmente por centrifugação a $9000 \mathrm{~g}$ por 10 minutos a $4^{\circ} \mathrm{C}$. O sobrenadante foi desprezado, os "pellets" foram misturados, obtendo-se uma concentração de $9,5 \times 10^{13} \mathrm{UFC} / \mathrm{mL}$.

\subsubsection{Preparação final do probiótico}

O pellet foi misturado com fubá (controlado previamente para a ausência de Salmonella spp.), na proporção de $20 \mathrm{~g}$ de probiótico e $980 \mathrm{~g}$ de fubá. Desta maneira, obteve-se uma concentração bacteriana final de $1,6 \times 10^{11} \mathrm{UFC} / \mathrm{g}$ de produto.

\subsection{INFECÇÃO EXPERIMENTAL}

\subsubsection{Amostra bacteriana}

Utilizou-se uma cepa patogênica de Salmonella enterica subsp enterica sorotipo Typhimurium (1796 NR), isolada de uma amostra de campo, resistente ao ácido nalidíxico $(100 \mu \mathrm{g} / \mathrm{mL}$ de meio), gentilmente 
cedida ao Laboratorio de Ornitopatología da Faculdade de Medicina Veterinária e Zootecnia da USP pelo Dr. J. S. Bailey do Departamento de Agricultura dos Estados Unidos (USDA-Athens-GA-USA).

\subsubsection{Determinação da concentração bacteriana para desafio das aves}

As aves de corte da linhagem Ross de um dia de idade, foram infectadas da seguinte maneira: uma cultura de Salmonella enterica subsp enterica sorotipo Typhimurium (1796 NR), resistente ao ácido nalidíxico $\left(100 \mu \mathrm{g} / \mathrm{mL}\right.$ de meio), foi semeada em caldo $\mathrm{BHI}$ (Apêndice 4 ) a $37^{\circ} \mathrm{C}$ por 24 horas. Foram realizadas diluições seriadas para a determinação das unidades formadoras de colônia (UFC).

As aves foram desafiadas com aproximadamente $10^{7} \mathrm{UFC} / \mathrm{mL}$. A suspensão bacteriana foi administrada via oral com uma cánula. O esquema de desafio está descrito na Tabela $2 b$.

\subsubsection{Desafio}

Todas as aves foram tratadas de acordo com o tratamento de cada grupo, como descrito na Tabela 1. Em cada grupo dos tratamentos com exclusão competitiva (Tabela 2a), 10 pintinhos foram desafiados com ST e sacrificados no setimo dia seguindo o protocolo de Mead et al. (1989), para o reisolamento de Salmonella Typhimurium $\mathrm{Nal}^{r}$ e avaliação de $\operatorname{lgG}$ e IgA no conteúdo intestinal. As demais aves de cada grupo continuaram recebendo os tratamentos até o dia 23 onde foram desafiadas 
semanalmente com Salmonella Typhimurium $\mathrm{Nal}^{\mathrm{r}}$ (1796 NR) e no dia 28 foram sacrificadas para a colheita de amostras (Tabela 2b).

Tabela 2a - Delineamento experimental dos grupos tratados com Exclusão Competitiva (EC*) e suas associações

\begin{tabular}{|c|c|c|}
\hline Tratamento & Grupo & Número de aves \\
\hline $\mathrm{T} 1$ & $1 \mathrm{a}$ & 10 \\
\hline \multicolumn{3}{|l|}{$\mathrm{EC}$} \\
\hline $\mathrm{T} 4$ & $4 a$ & 10 \\
\hline \multicolumn{3}{|l|}{$E C+$ LEB } \\
\hline T5 & $5 a$ & 10 \\
\hline \multicolumn{3}{|l|}{$E C+G$} \\
\hline T6 & $6 a$ & 10 \\
\hline \multicolumn{3}{|l|}{$E C+L E B+G$} \\
\hline T8 & $8 a$ & 10 \\
\hline \multicolumn{3}{|l|}{ Controle (-) } \\
\hline T9 & $9 a$ & 10 \\
\hline \multicolumn{3}{|l|}{ Controle $(+)$} \\
\hline TOTAL & 6 grupos & $60^{* *}$ \\
\hline
\end{tabular}


Tabela 2b- Delineamento experimental dos tratamentos durante o período do experimento

\begin{tabular}{|c|c|c|c|c|c|}
\hline Tratamento & Grupo & $\begin{array}{c}\text { Número } \\
\text { aves }\end{array}$ & Repetição & Desafio & $\begin{array}{l}\text { Colheita de soro / lavagem } \\
\text { intestinal / amostras para } \\
\text { reisolamento de ST }\end{array}$ \\
\hline \multirow{3}{*}{$\mathrm{T} 1$} & $1 b$ & 10 & 1 & Dia 09 & Dia 14 \\
\hline & $1 c$ & 10 & 2 & Dia 16 & Dia 21 \\
\hline & $1 d$ & 10 & 3 & Dia 23 & Dia 28 \\
\hline \multirow{4}{*}{$\mathrm{T} 2$} & $2 a$ & 10 & 1 & Dia 01 & $\operatorname{Dia} 7^{*}$ \\
\hline & $2 b$ & 10 & 2 & Dia 09 & Dia 14 \\
\hline & $2 c$ & 10 & 3 & Dia 16 & Dia 21 \\
\hline & $2 d$ & 10 & 4 & Dia 23 & Dia 28 \\
\hline \multirow{4}{*}{ T3 } & $3 a$ & 10 & 1 & Dia 01 & $\operatorname{Dia} 7^{*}$ \\
\hline & $3 b$ & 10 & 2 & Dia 09 & Dia 14 \\
\hline & $3 c$ & 10 & 3 & Dia 16 & Dia 21 \\
\hline & $3 d$ & 10 & 4 & Dia 23 & Dia 28 \\
\hline \multirow{3}{*}{ T4 } & $4 b$ & 10 & 1 & Dia 09 & Dia 14 \\
\hline & $4 c$ & 10 & 2 & Dia 16 & Dia 21 \\
\hline & $4 d$ & 10 & 3 & Dia 23 & Dia 28 \\
\hline \multirow{3}{*}{ T5 } & $5 b$ & 10 & 1 & Dia 09 & Dia 14 \\
\hline & $5 c$ & 10 & 2 & Dia 16 & Dia 21 \\
\hline & $5 d$ & 10 & 3 & Dia 23 & Dia 28 \\
\hline \multirow{3}{*}{ T6 } & $6 b$ & 10 & 1 & Dia 09 & Dia 14 \\
\hline & $6 c$ & 10 & 2 & Dia 16 & Dia 21 \\
\hline & $6 \mathrm{~d}$ & 10 & 3 & Dia 23 & Dia 28 \\
\hline \multirow{4}{*}{$\mathrm{T7}$} & $7 a$ & 10 & 1 & Dia 01 & Dia $7^{*}$ \\
\hline & $7 b$ & 10 & 2 & Dia 09 & Dia 14 \\
\hline & $7 c$ & 10 & 3 & Dia 16 & Dia 21 \\
\hline & $7 d$ & 10 & 4 & Dia 23 & Dia 28 \\
\hline \multirow{3}{*}{$\mathrm{T}^{\mathrm{a}}$} & $8 b$ & 10 & 1 & Sem & Dia 14 \\
\hline & $8 c$ & 10 & 2 & desafio & Dia 21 \\
\hline & $8 d$ & 10 & 3 & & Dia 28 \\
\hline \multirow{3}{*}{$T 9^{b}$} & $9 b$ & 10 & 1 & Dia 09 & Dia 14 \\
\hline & $9 c$ & 10 & 2 & Dia 16 & Dia 21 \\
\hline & $9 d$ & 10 & 3 & Dia 23 & Dia 28 \\
\hline TOTAL & 9 & 300 & 30 & & \\
\hline
\end{tabular}




\subsection{OBTENÇÃO DE AMOSTRAS}

\subsubsection{Amostras de soro}

A coleta de soro se realizou em todos os tratamentos, nos dias 0 , 14, 21 e 28 do experimento. No dia 0 do experimento se sacrificaram 35 pintinhos adicionais, da mesma origem e procedência, para se estabelecer os valores médios de anticorpos no soro e no intestino, assim como, a determinação de colonização e invasão por Salmonella spp.

O soro foi separado, colocado em criotubos e centrifugado a $2655 \mathrm{~g}$ por 10 minutos a $4^{\circ} \mathrm{C}$. O soro foi colhido, colocado em criotubos, identificado e estocado a $-20^{\circ} \mathrm{C}$ até sua utilização para a realização do teste de ELISA.

\subsubsection{Amostras de conteúdo intestinal}

O conteúdo intestinal foi obtido como indica o procedimento descrito a seguir, das mesmas aves onde se obteve o soro para a quantificação de $\lg G$ e $\lg A$.

As amostras de conteúdo intestinal para a detecção de anticorpos (IgG e SlgA) foram obtidas de intestino seguindo a seguinte sequência:

- Foi removido todo o intestino desde o duodeno até o reto.

- A gordura adjacente do intestino e o pâncreas foram removidas.

- O intestino foi segmentado em três ou quatro partes, para facilitar a manipulação.

- O conteúdo foi removido e acondicionado em um tubo contendo de 2 a $5 \mathrm{~mL}$ de tampão fosfato salino (PBS 0,1M pH 7,4) 
contendo uma mistura de inibidores de proteases (EDTA, PMSF, Pepstatina e Leupeptina) $)^{4}$, mantendo o tubo sempre em banho de gelo. A concentração dos inibidores utilizados está descrita na Tabela 3.

Tabela 3- Inibidores de proteases utilizados

\begin{tabular}{cc}
\hline Inibidores & Concentração \\
\hline EDTA & $\mathbf{0 , 3} \mathbf{m g} / \mathbf{m L}$ \\
PMSF & $\mathbf{7 5} \boldsymbol{\mu g} / \mathbf{m L}$ \\
Pepstatina & $\mathbf{0 , 7 \mu g / m L}$ \\
Leupeptina & $0,5 \mu \mathrm{g} / \mathrm{mL}$ \\
\hline
\end{tabular}

- O conteúdo intestinal foi centrifugado a $10000 \mathrm{~g}$ por 15 minutos a $4^{\circ} \mathrm{C}$. Em seguida, o sobrenadante foi retirado e cetrifugado novamente a $10000 \mathrm{~g}$ por 10 minutos a $4^{\circ} \mathrm{C}$.

- Assim, obteve-se de 3 a 4 alíquotas de $1 \mathrm{~mL}$ que foram armazenadas a $-20^{\circ} \mathrm{C}$ até a realização do teste de ELISA.

\subsubsection{Reisolamento de Salmonella Typhimurium $\mathrm{Nal}^{\mathrm{r}}$ de amostras de cecos e órgaõs internos}

Para a avaliação da colonização, os cecos foram removidos com pinça e tesoura estéril, e acondicionados em sacos plásticos estéreis previamente pesados. Em cada saco plástico foi colocado de 9 a $15 \mathrm{~mL}$ de água peptonada $0,1 \%, \mathrm{pH} 7,0$. O volume utilizado foi variável dependendo da idade 
das aves e do tamanho da amostra, procurando manter a proporção de $10 \%$. Uma amostra de $0,1 \mathrm{~mL}$ de cada saco plástico, foi semeada no meio $\mathrm{XLT}_{4}$ (Apêndice) contendo $100 \mu \mathrm{g} / \mathrm{mL}$ de ácido nalidíxico e foi mantida a $37^{\circ} \mathrm{C}$, por 24 a 96 horas.

Para avaliar a invasão da amostra de Salmonella Typhimurium Nal ${ }^{r}$ nos órgãos, o fígado e baço foram removidos com pinça e tesoura estéreis, e acondicionados separadamente em sacos plásticos estéreis, previamente pesados. Em cada saco plástico foi colocado de 9 a $15 \mathrm{~mL}$ de água peptonada $0,1 \%, \mathrm{pH} 7,0$. O volume utilizado foi variável dependendo da idade das aves e do tamanho da amostra, procurando manter a proporção de $10 \%$. Em meio $\mathrm{XLT}_{4}$ adicionado de ácido nalidíxico $100 \mathrm{ug} / \mathrm{mL}$, semeou-se 0,1 mL de cada amostra de fígado ou baço. A placa foi incubada a $37^{\circ} \mathrm{C}$ por 24 a 96 horas. As colônias suspeitas foram submetidas a série bioquímica e a reação de aglutinação rápida com soro anti-antígeno somático de Salmonellae para a confirmação bacteriana.

Finalmente, se calculou as unidades formadoras de colônia por grama (UFC/g) para as amostras de ceco e dos órgãos, que foram expressos em $\log _{10}$ UFC Salmonella/g.

\subsubsection{Delineamento experimental}

Foram realizados paralelamente dois testes:

a) nos grupos tratados com produtos de exclusão competitiva (Tabela 2a) as aves foram desafiadas no dia 1 do experimento e sacrificados 5 dias após o desafio, segundo o protocolo de Mead et al. [1989]. 
b) todos os grupos (Tabela $2 \mathrm{~b}$ ) tratados no período completo do experimento e desafiados no dia 23, foram sacrificados uma semana após o desafio, com exceção do grupo T8, controle negativo. A coleta de amostras: soro, cecos e órgãos internos (fígado e baço) foram realizadas segundo a Tabela 2b.

\subsection{DETECÇÃO E QUANTIFICAÇÃO DE IgG e IgA NO SORO E CONTEÚDO INTESTINAL}

A quantificação de $\lg G$ e $\lg A$ no soro e no conteúdo intestinal foi realizada através do teste de ELISA ${ }^{5}$. O limite de detecção para IgG foi de $200-3,12 \mathrm{ng} / \mathrm{mL}$ e para $\lg A$ de $1000-15,625 \mathrm{ng} / \mathrm{mL}$, tanto no soro como no conteúdo intestinal.

\section{Cálculos de concentração:}

Os cálculos da concentração de $\lg G$ e de $\lg A$ a partir da absorbância foram expressos em ng/mL. Através da absorbância (y) encontrada, foram realizados os cálculos utilizando a fórmula de ajuste para quatro parâmetros logísticos como segue:

$$
y=\left[(A-D) /\left(1+\{x / c\}^{B}\right)\right]+D
$$

Onde:

$$
\begin{aligned}
& y-D=A-D / 1+(x / c)^{B} \\
& y-D / A-D=1 / 1+(x / c)^{B}
\end{aligned}
$$

\footnotetext{
${ }^{5}$ Bethyl Lab., Inc (Montgomery, Texas - USA)
} 


$$
\begin{aligned}
& A-D / y-D=1+(x / C)^{B} \\
& {[A-D / y-D]-1=K} \\
& K=[x / C]^{B} \\
& K^{1 / B}=x / C \\
& \left.x=C K^{1 / B} \text { (concentração final em } n g / m L\right)
\end{aligned}
$$

Para IgG os valores pré-estabelecidos de A, B, C e D foram: $A=0.148$, $B=1.345, C=39.286$ e $D=2.139$.

Para IgA os valores pré-estabelecidos de $A, B, C$ e $D$ foram: $A=0.05$, $B=1.142, C=636.601$ e $D=3.216$.

\subsection{EFICÁCIA DOS TRATAMENTOS}

A eficácia dos tratamentos quando foram utilizados produtos de exclusão competitiva (Tabela 2a), foi avaliada pela metodologia recomendada por Mead et al. (1989), calculando-se o fator de infectividade (IF) e o fator de proteção (PF).

Para avaliar a eficácia dos tratamentos em relação à colonização de Salmonella enterica subsp. enterica sorotipo Typhimirium nos cecos, realizouse culturas de amostras dos cecos e conteúdo cecal. Em relação à invasão nos órgãos internos, foram realizadas culturas de amostras de fígado e baço, sendo os resultados expressos em $\log _{10}$ UFC Salmonella/g. 


\subsection{ANÁLISE ESTATÍSTICA}

Para os tratamentos que usaram exclusão competitiva se estabeleceu o grau de infectividade (IF) obtido através do número de unidades formadoras de colônias reisoladas, por grama de material fecal. O fator de proteção (PF) foi determinado pela relação do fator de infectividade do grupo controle em relação ao grupo tratado (MEAD et al., 1989).

Para a comparação entre os tratamentos, tanto de colonização e invasão como de resposta imune, utilizou-se ANOVA e o teste de Duncan [SPIEGEL, 1993]. Os resultados foram expressos em termos de probabilidade $(p<0,05)$. 


\section{$4 \quad$ RESULTADOS}

A Tabela 4 descreve os níveis de colonização dos cecos e invasão dos órgãos, após o desafio com Salmonella Typhimurium $\mathrm{Nal}^{\mathrm{r}}$ em todos os grupos que receberam exclusão competitiva e suas associações, de acordo com o protocolo de Mead et al. [1989]. A Tabela 5 mostra o fator de infecção (IF) e o fator de proteção (PF) para cada um dos tratamentos avaliados. Nos grupos onde houve tratamento com o produto de exclusão competitiva, a colonização nos cecos na primeira semana de idade foi observada no T1 (tratamento somente com EC) e no grupo T9 (controle positivo). Entre ambos grupos houve diferenças significativas nas UFC/g para a invasão no baço $(p<0,05)$. Em todos os grupos foi observada a colonização dos cecos, no entanto os tratamentos T5 $(E C+G)$ e T6 $(E C+L E B+G)$ apresentaram uma maior redução na invasão em relação aos demais grupo $(p<0,05)$.

A Tabela 5 mostra os resultados para o fator de infectividade (IF) e para o fator de proteção, de acordo com Mead et al. [1989]. O menor IF indicou que houve baixos níveis de colonização por Salmonella Typhimurium $\mathrm{Nal}^{\mathrm{r}}$, sendo estes observados nos grupo T6 (EC+LEB+G) e T5 $(E C+G)$, em ordem de importância. Igualmente, o valor PF maior indica o tratamento mais eficaz, que foi o T6 $(E C+L E B+G)$, sendo que os tratamentos com valores de PF superiores a 4 são considerados eficazes.

A Tabela 6 mostra os resultados dos valores referenciais médios no dia 0 do experimento, para IgG e IgA em soros e conteúdo intestinal de aves de um dia de 
idade. Como pode ser verificado nos resultados, as aves mostraram níveis médios de IgG no soro de $156,46 \mathrm{ng} / \mathrm{mL}$, e no conteúdo intestinal $115,12 \mathrm{ng} / \mathrm{mL}$. Com relação a IgA no soro o nível mínimo foi de $21,11 \mathrm{ng} / \mathrm{mL}$ e no conteúdo intestinal foi de $386,91 \mathrm{ng} / \mathrm{mL}$, neste grupo de referência não houve isolamento de Salmonella quando realizadas as culturas de cecos e órgãos internos.

Durante a primeira semana, não foi feita a quantificação de $\lg G$ e $\lg A$ nos soros devido à interferência da imunidade materna nos resultados. No conteúdo intestinal a avaliação durante a primeira semana quando comparados com o dia 0 do experimento, mostrou uma redução significativa em todos os tratamentos $(p<0,05)$.

A tabela 7 detalha a concentração de $\operatorname{lgG}$ em soros, medidos a partir da segunda semana do experimento. As diferenças significativas $(p<0,05)$ em cada semana e entre grupos estão indicadas nesta tabela. Na coluna correspondente à segunda semana, pode ser confirmado pela comparação com o grupo controle negativo (T8) nessa semana, que existe uma evidência de anticorpos maternos. $\mathrm{Na}$ terceira e quarta semana pode observar-se apesar das diferenças significativas em alguns grupo, que os níveis de lgG nos soros diminuíram consideravelmente, mantendo-se em equilibrio durante as últimas duas semanas do experimento, sem evidências de estímulo imune nos tratamentos.

A Figura 1, mostra o comportamento da curva de concentração para cada tratamento referente a $\lg G$ no soro. Não houve diferenças significativas, na concentração média de lgG nos tratamentos T3 (G), T4 (EC+LEB) e T7 (LEB+G), durante a terceira e quarta semana, onde os valores se mantiveram estáveis. Uma 
diminuição drástica, pode ser observada no período do inicio do experimento até a terceira semana independente do tratamento utilizado, havendo neste caso uma diferença significativa a partir da terceira semana $(p<0,05)$.

A Tabela 8 mostra os valores da concentração média de IgG no conteúdo intestinal desde a primeira semana. Os valores foram obtidos desde a primeira semana, para quantificar a produção de anticorpos no intestino em todos os tratamentos e avaliar a sua correlação com a colonização intestinal e invasão dos órgãos pela cepa de desafio Salmonella Typhimurium Nal' ${ }^{r}$ Apesar de existirem algumas diferenças significativas dentro da mesma semana e entre semanas dependendo do grupo de tratamento, os níveis de IgG no conteúdo intestinal mantiveram-se estáveis, e não existe evidências de um estímulo para a síntese desta imunoglobulina.

A Figura 2, mostra as curvas de concentração de lgG no conteúdo intestinal durante todo o experimento. Observou-se uma redução significativa $(p<0,05)$ na primeira semana, quando comparado com o valor de referência do dia 0 do experimento, e reflete os resultados da Tabela 8.

A Tabela 9 mostra os valores da concentração média de $\lg A$ em soros. Não houve diferenças significativas no grupo T7 $(\mathrm{LEB}+\mathrm{G})$ quando foram comparados os resultados obtidos nas diferentes semanas de tratamento, mantendo-se estáveis os níveis de anticorpos. Porém, como pode ser observado na Figura 3, quando os valores foram comparados com o valor de referência no dia 0 do experimento, verificou-se um aumento drástico dos níveis séricos de $\lg A$ em todos os tratamentos. 
O comportamento da curva do tratamento $\mathrm{T} 7$, mostra uma resposta constante mantendo um nível estável e elevado desde a segunda semana do experimento.

A Tabela 10, mostra a concentração média de $\lg A$ no conteúdo intestinal medidos desde a primeira semana. No dia 0 do experimento as aves chegaram com uma média de $368,91 \mathrm{ng} / \mathrm{mL}$. Na primeira semana, houve uma diminuição em todos os tratamentos, embora tenham sido observadas diferenças significativas $(p<0,05)$ nos grupos T6 $(E C+L E B+G)$ e T7 $(L E B+G)$ quando comparados com os outros grupos. A partir da segunda semana, não foram observadas diferenças significativas no grupo T6, que manteve os níveis de anticorpos estáveis durante todo o periodo de tratamento. A comparação gráfica do comportamento das concentrações médias de IgA no conteúdo intestinal, pode ser encontrada na Figura 4, onde apesar da tendência das curvas serem similares, observou-se diferenças significativas $(p<0,05)$ nas concentrações dentro dos grupos e entre grupos.

As Figuras 5 e 6 mostram as concentrações de $\operatorname{lgA}$ no soro e conteúdo intestinal, respectivamente, durante todo o período do experimento .

As Tabelas 11, 12 e 13 mostram os níveis de colonização dos cecos e invasão dos órgãos após o desafío, na segunda, terceira e quarta semana do experimento; indicando as diferenças significativas $(p<0,05)$ entre os tratamentos.

A Tabela 11, correspondente à segunda semana, apesar da dose de desafio ter sido alta $\left(10^{7} \mathrm{UFC} / \mathrm{mL}\right)$, observou-se que ST pode ser recuperada de todas as amostras de cecos e conteúdo cecal, porém a invasão dos órgãos, especialmente 
do fígado não foi observada nos tratamentos T6 (EC+LEB+G) e T7 (LEB+G). E ST não foi reisolada do baço nos tratamentos $T 5(E C+G), \quad T 6(E C+L E B+G)$ e $\mathrm{T} 7(\mathrm{LEB}+\mathrm{G})$.

A Tabela 12, que correspondeu à terceira semana de idade, mostra a ausência de invasão dos órgãos em todos os tratamentos, exceto no grupo T3 tratado somente com glucano, onde observou-se a invasão de fígado em uma das aves. Porém, a colonização dos cecos foi observada em todos os grupos de tratamento, sendo que houve uma redução significativa na colonização $(p<0,05)$, quando comparado com os dados de colonização da segunda semana (Tabela 11).

A Tabela 13, correspondente à quarta semana de idade, mostrou a colonização por Salmonella em uma ave do grupo tratado com o produto EC e em três aves do grupo controle positivo. Este resultado indica o aumento da resistência natural para a colonização de Salmonella Typhimurium $\mathrm{Nal}^{r}$ na quarta semana de vida das aves, e houve diferenças significativas $(p<0,05)$ na colonização entre os grupos positivos. Não foi observado neste período invasão dos órgãos internos em nenhum grupo e no grupo controle positivo. 
Tabela 4- Média de $\log _{10}$ UFC Salmonella/g em amostras de aves tratadas com produto de EC e suas associações, na primeira semana de idade

\begin{tabular}{ccccccc}
\hline & \multicolumn{2}{c}{ Média Log ${ }_{10}$ UFC Salmonella/g } & \multicolumn{2}{c}{ Positivos (positivos/total) } \\
\cline { 2 - 7 } Tratamento & Ceco & Fígado & Baço & Ceco & Fígado & Baço \\
\hline T1 & $3,23^{\mathrm{b}}$ & $2,43^{\mathrm{a}}$ & $4,15^{\mathrm{c}}$ & $6 / 10$ & $1 / 10$ & $1 / 10$ \\
T4 & $2,46^{\mathrm{a}}$ & $0^{\mathrm{b}}$ & $0^{\mathrm{b}}$ & $4 / 10$ & 0 & 0 \\
T5 & $2,42^{\mathrm{a}}$ & $0^{\mathrm{b}}$ & $0^{\mathrm{b}}$ & $2 / 10$ & 0 & 0 \\
T6 & $2,79^{\mathrm{a}}$ & $0^{\mathrm{b}}$ & $0^{\mathrm{b}}$ & $1 / 10$ & 0 & 0 \\
T8 & $0^{\mathrm{b}}$ & $0^{\mathrm{b}}$ & $0^{\mathrm{b}}$ & 0 & 0 & 0 \\
T9 & $3,99^{\mathrm{c}}$ & $2,41^{\mathrm{a}}$ & $1,29^{\mathrm{d}}$ & $8 / 9$ & $1 / 9$ & $1 / 9$ \\
\hline Valores com letras diferentes, tiveram diferenças significativas (p<0,05) & & & \\
\hline
\end{tabular}


Tabela 5- Fator de infectividade (IF) e Fator de proteção (FP), em aves tratadas com produtos de EC e suas associações na primeira semana de idade.

\begin{tabular}{|c|c|c|c|c|c|c|c|c|}
\hline \multirow[t]{2}{*}{ Tratamento } & \multicolumn{6}{|c|}{$\begin{array}{l}\text { Número de aves infectadas } \\
\left(\text { Log }_{10} \text { UFC Salmonella/g) }\right.\end{array}$} & \multirow{2}{*}{$\begin{array}{c}\text { Fator de } \\
\text { Infectividade* } \\
\text { (IF) }\end{array}$} & \multirow[t]{2}{*}{$\begin{array}{c}\text { Fator de proteção } \\
\text { (PF) }\end{array}$} \\
\hline & 0 & 1 & 2 & 3 & 4 & 5 & & \\
\hline T1 & 4 & 0 & 2 & 4 & 0 & 0 & 1.6 & $1.75(40 \%)$ \\
\hline T4 & 6 & 2 & 0 & 1 & 1 & 0 & 0.9 & $3.11(60 \%)$ \\
\hline T5 & 8 & 1 & 0 & 1 & 0 & 0 & 0.4 & $7,0(80 \%)$ \\
\hline T6 & 9 & 0 & 1 & 0 & 0 & 0 & 0.2 & $14,0(90 \%)$ \\
\hline T8 & 10 & 0 & 0 & 0 & 0 & 0 & 0 & $>28(100 \%)$ \\
\hline T9 & 1 & 0 & 1 & 2 & 5 & 0 & 2.8 & $1,0(11.1 \%)$ \\
\hline
\end{tabular}

${ }^{*}$ Mead et al, 1989. 
Tabela 6- Valores médios referenciais de concentração de $\lg G$ e $\lg A$ (ng/mL), no dia 0 do experimento.

\begin{tabular}{lc}
\hline Anticorpo & $\begin{array}{c}\text { Valores médios de concentração } \\
(\mathrm{ng} / \mathrm{mL})\end{array}$ \\
\hline IgG em soro & $156,46^{\mathrm{c}}$ \\
IgG em conteúdo intestinal & $115,12^{\mathrm{b}}$ \\
IgA em soro & $21,11^{\mathrm{a}}$ \\
IgA em conteúdo intestinal & $368,91^{\mathrm{d}}$ \\
\hline
\end{tabular}


Tabela 7- Concentração média de $\operatorname{lgG}(\mathrm{ng} / \mathrm{mL})$ em soros, durante o período do experimento.

\begin{tabular}{cccc}
\hline Tratamento & $\begin{array}{r}\text { Segunda } \\
\text { semana }\end{array}$ & $\begin{array}{c}\text { Terceira } \\
\text { Semana }\end{array}$ & $\begin{array}{c}\text { Quarta } \\
\text { semana }\end{array}$ \\
\hline T1 & $115,44^{\mathrm{a}}$ & $77,47^{\mathrm{c}}$ & $49,39^{\mathrm{e}}$ \\
T2 & $145,17^{\mathrm{b}}$ & $32,47^{\mathrm{d}}$ & $46,05^{\mathrm{e}}$ \\
T3 & $106,78^{\mathrm{a}}$ & $33,46^{\mathrm{d}}$ & $36,57^{\mathrm{d}}$ \\
T4 & $78,92^{\mathrm{c}}$ & $48,21^{\mathrm{e}}$ & $47,38^{\mathrm{e}}$ \\
T5 & $100,99^{\mathrm{a}}$ & $48,97^{\mathrm{e}}$ & $55,34^{\mathrm{f}}$ \\
T6 & $116,91^{\mathrm{a}}$ & $52,24^{\mathrm{e}}$ & $38,73^{\mathrm{d}}$ \\
T7 & $98,89^{\mathrm{a}}$ & $51,72^{\mathrm{e}}$ & $52,41^{\mathrm{e}}$ \\
T8 & $109,15^{\mathrm{a}}$ & $56,25^{\mathrm{f}}$ & $44,76^{\mathrm{e}}$ \\
T9 & $106,37^{\mathrm{a}}$ & $73,58^{\mathrm{c}}$ & $40,41^{\mathrm{e}}$
\end{tabular}


Figura 1 - Concentrações médias de lgG (ng/mL) em soros

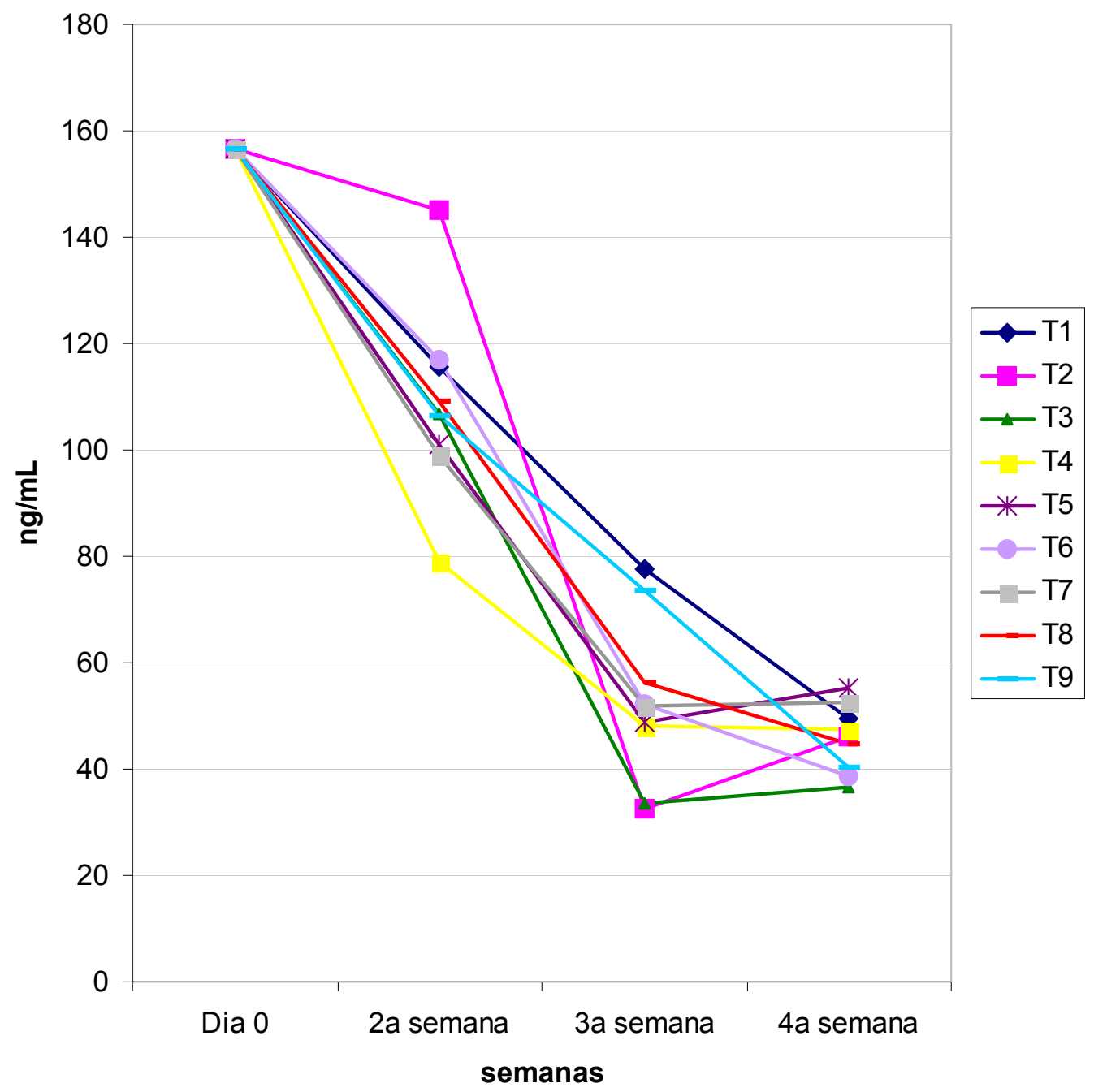


Tabela 8- Concentração de lgG ( $\mathrm{ng} / \mathrm{mL})$ em conteúdo intestinal durante todo o período do experimento.

\begin{tabular}{ccccc}
\hline Tratamento & $\begin{array}{c}\text { Primeira } \\
\text { semana }\end{array}$ & $\begin{array}{c}\text { Segunda } \\
\text { semana }\end{array}$ & $\begin{array}{c}\text { Terceira } \\
\text { semana }\end{array}$ & $\begin{array}{c}\text { Quarta } \\
\text { semana }\end{array}$ \\
\hline T1 & $18,59^{\mathrm{a}}$ & $21,36 \mathrm{~b}$ & $18,94^{\mathrm{a}}$ & $15,79^{\mathrm{a}}$ \\
T2 & $16,23^{\mathrm{a}}$ & $18,19^{\mathrm{a}}$ & $15,84^{\mathrm{a}}$ & $16,89^{\mathrm{a}}$ \\
T3 & $15,27^{\mathrm{a}}$ & $15,78^{\mathrm{a}}$ & $18,08^{\mathrm{a}}$ & $15,41^{\mathrm{a}}$ \\
T4 & $23,18^{\mathrm{b}}$ & $20,76 \mathrm{~b}$ & $16,56^{\mathrm{a}}$ & $16,17^{\mathrm{a}}$ \\
T5 & $21,84^{\mathrm{b}}$ & $17,23^{\mathrm{a}}$ & $17,12^{\mathrm{a}}$ & $13,96^{\mathrm{b}}$ \\
T6 & $21,42^{\mathrm{b}}$ & $16,01^{\mathrm{a}}$ & $14,92^{\mathrm{a}}$ & $18,02^{\mathrm{a}}$ \\
T7 & $15,17^{\mathrm{a}}$ & $16,28^{\mathrm{a}}$ & $21,72^{\mathrm{b}}$ & $15,89^{\mathrm{a}}$ \\
T8 & $24,05^{\mathrm{b}}$ & $22,32^{\mathrm{b}}$ & $20,82^{\mathrm{b}}$ & $17,18^{\mathrm{a}}$ \\
T9 & $28,17^{\mathrm{c}}$ & $17,56^{\mathrm{a}}$ & $17,45^{\mathrm{a}}$ & $15,29^{\mathrm{a}}$ \\
\hline
\end{tabular}


Figura 2 - Concentrações médias de $\operatorname{lgG}(\mathrm{ng} / \mathrm{mL})$ no conteúdo intestinal

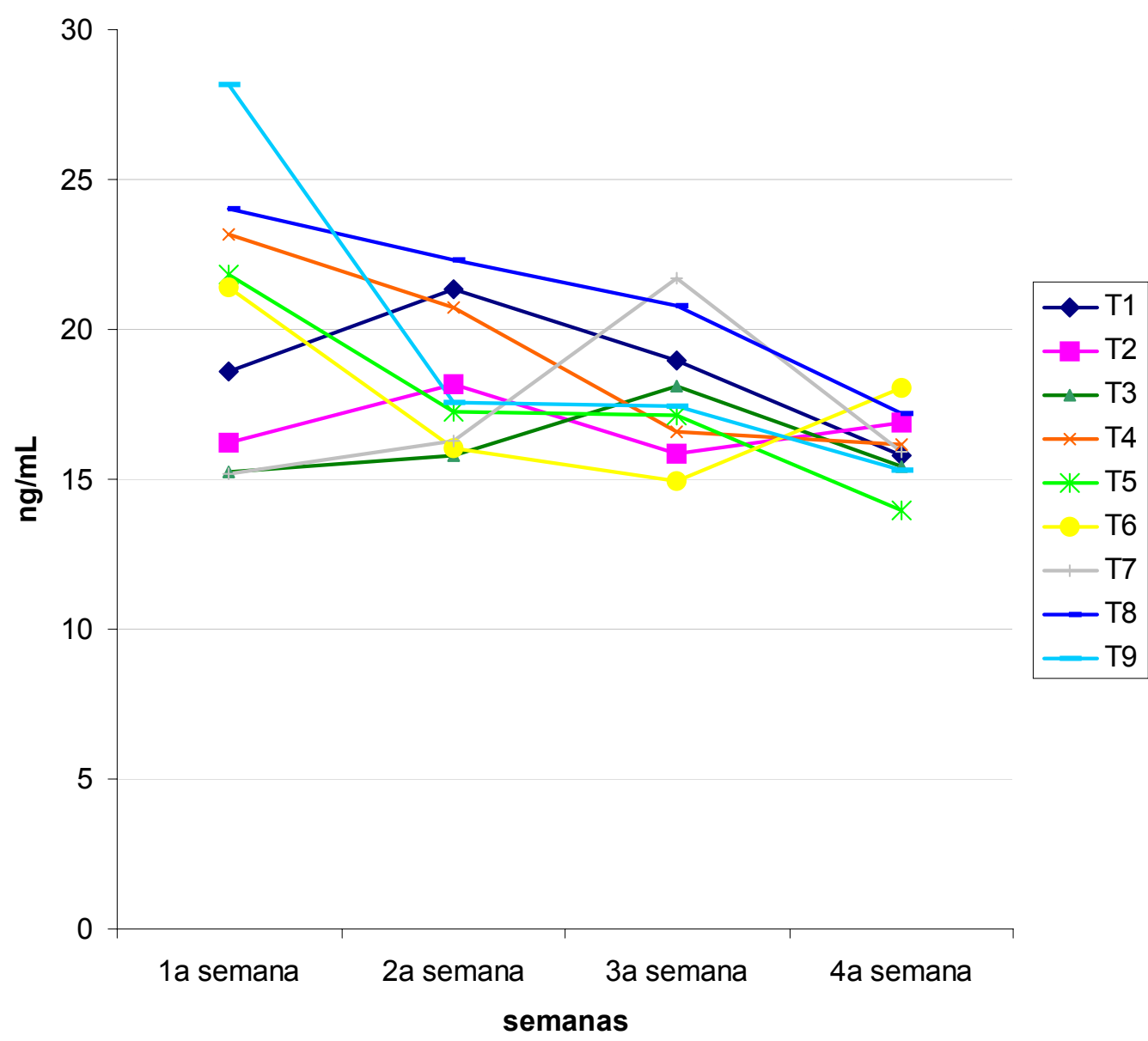


Tabela 9- Concentração média de $\lg A(\mathrm{ng} / \mathrm{mL})$ em soros durante o período do experimento.

\begin{tabular}{cccc}
\hline Tratamento & $\begin{array}{c}\text { Segunda } \\
\text { semana }\end{array}$ & $\begin{array}{c}\text { Terceira } \\
\text { Semana }\end{array}$ & $\begin{array}{c}\text { Quarta } \\
\text { Semana }\end{array}$ \\
\hline T1 & $502,94^{\mathrm{a}}$ & $440,35^{\mathrm{b}}$ & $351,77^{\mathrm{c}}$ \\
T2 & $481,94^{\mathrm{a}}$ & $321,01^{\mathrm{c}}$ & $355,33^{\mathrm{c}}$ \\
T3 & $439,70^{\mathrm{b}}$ & $340,36^{\mathrm{c}}$ & $258,97^{\mathrm{d}}$ \\
T4 & $418,13^{\mathrm{b}}$ & $325,62^{\mathrm{c}}$ & $317,82^{\mathrm{c}}$ \\
T5 & $453,02^{\mathrm{b}}$ & $335,53^{\mathrm{c}}$ & $329,35^{\mathrm{c}}$ \\
T6 & $429,39^{\mathrm{b}}$ & $247,42^{\mathrm{d}}$ & $305,83^{\mathrm{c}}$ \\
T7 & $415,68^{\mathrm{b}}$ & $424,34^{\mathrm{b}}$ & $439,04^{\mathrm{b}}$ \\
T8 & $359,68^{\mathrm{c}}$ & $268,73^{\mathrm{d}}$ & $395,49^{\mathrm{b}}$ \\
T9 & $493,02^{\mathrm{a}}$ & $460,54^{\mathrm{b}}$ & $330,29^{\mathrm{c}}$ \\
\hline
\end{tabular}


Figura 3 - Concentrações médias de $\lg A(n g / m L)$ em soros

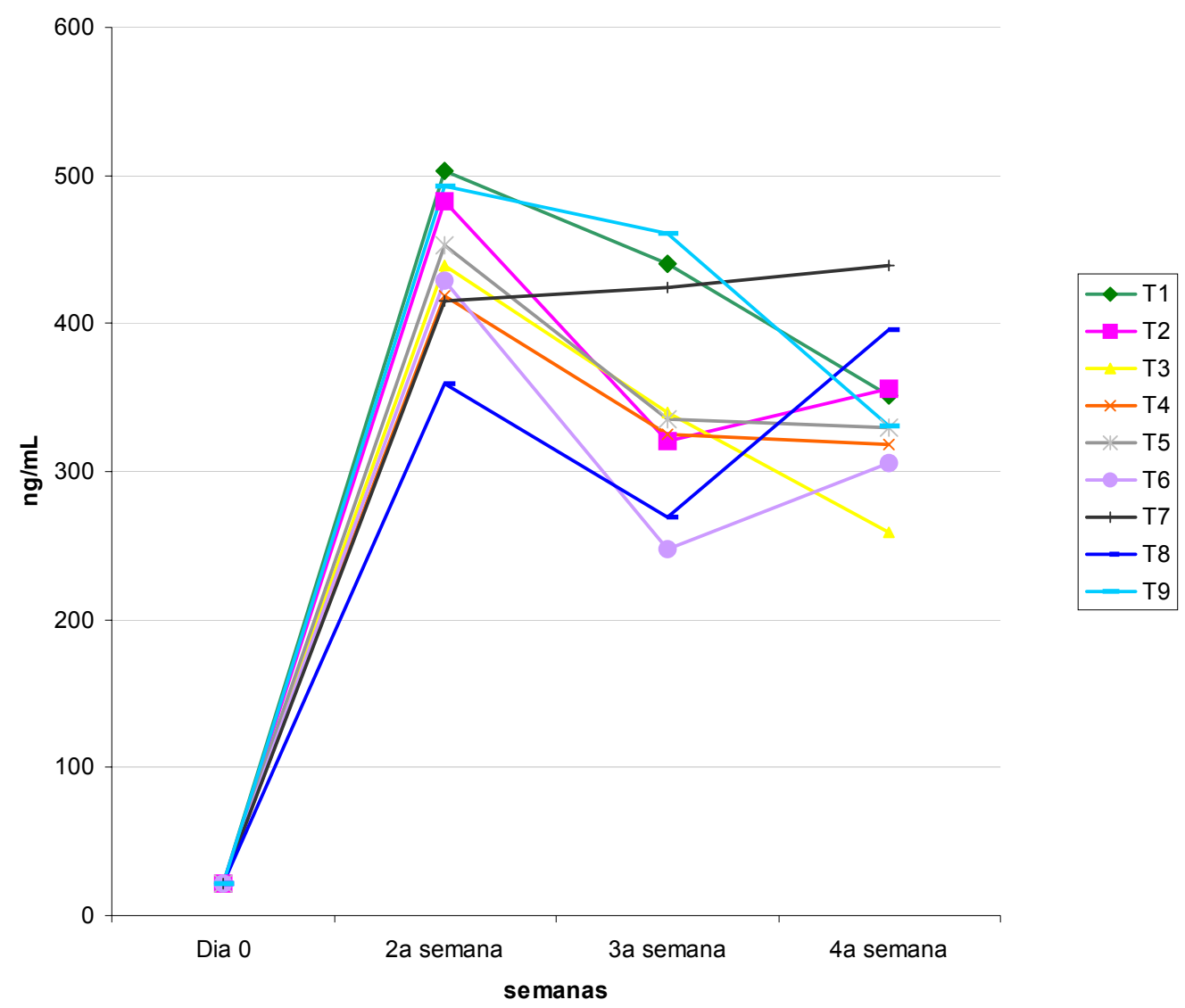


Tabela 10- Concentração média de $\operatorname{lgA}(\mathrm{ng} / \mathrm{mL})$ em conteúdo intestinal durante o período do experimento.

\begin{tabular}{ccccc}
\hline Tratamento & $\begin{array}{c}\text { Primeira } \\
\text { semana }\end{array}$ & $\begin{array}{c}\text { Segunda } \\
\text { semana }\end{array}$ & $\begin{array}{c}\text { Terceira } \\
\text { semana }\end{array}$ & $\begin{array}{c}\text { Quarta } \\
\text { semana }\end{array}$ \\
\hline T1 & $16,07^{\mathrm{a}}$ & $239,08^{\mathrm{f}}$ & $414,46^{\mathrm{j}}$ & $330,29^{\mathrm{i}}$ \\
T2 & $18,45^{\mathrm{a}}$ & $211,83^{\mathrm{f}}$ & $398,97^{\mathrm{h}}$ & $260,83^{\mathrm{g}}$ \\
T3 & $32,26^{\mathrm{b}}$ & $297,68^{\mathrm{g}}$ & $330,77^{\mathrm{i}}$ & $240,45^{\mathrm{f}}$ \\
T4 & $29,93^{\mathrm{b}}$ & $196,34^{\mathrm{e}}$ & $291,41^{\mathrm{g}}$ & $164,05^{\mathrm{c}}$ \\
T5 & $34,99^{\mathrm{b}}$ & $150,90^{\mathrm{c}}$ & $271,42^{\mathrm{g}}$ & $346,05^{\mathrm{i}}$ \\
T6 & $133,44^{\mathrm{c}}$ & $365,71^{\mathrm{h}}$ & $399,55^{\mathrm{h}}$ & $373,18^{\mathrm{h}}$ \\
T7 & $127,52^{\mathrm{c}}$ & $383,04^{\mathrm{h}}$ & $430,66^{\mathrm{j}}$ & $287,29^{\mathrm{g}}$ \\
T8 & $13,46^{\mathrm{a}}$ & $156,89^{\mathrm{c}}$ & $330,77^{\mathrm{i}}$ & $208,77^{\mathrm{f}}$ \\
T9 & $41,39^{\mathrm{d}}$ & $193,47^{\mathrm{e}}$ & $398,97^{\mathrm{h}}$ & $350,76^{\mathrm{h}}$ \\
\hline
\end{tabular}


Figura 4 - Concentrações médias de $\lg A(n g / m L)$ em conteúdo intestinal

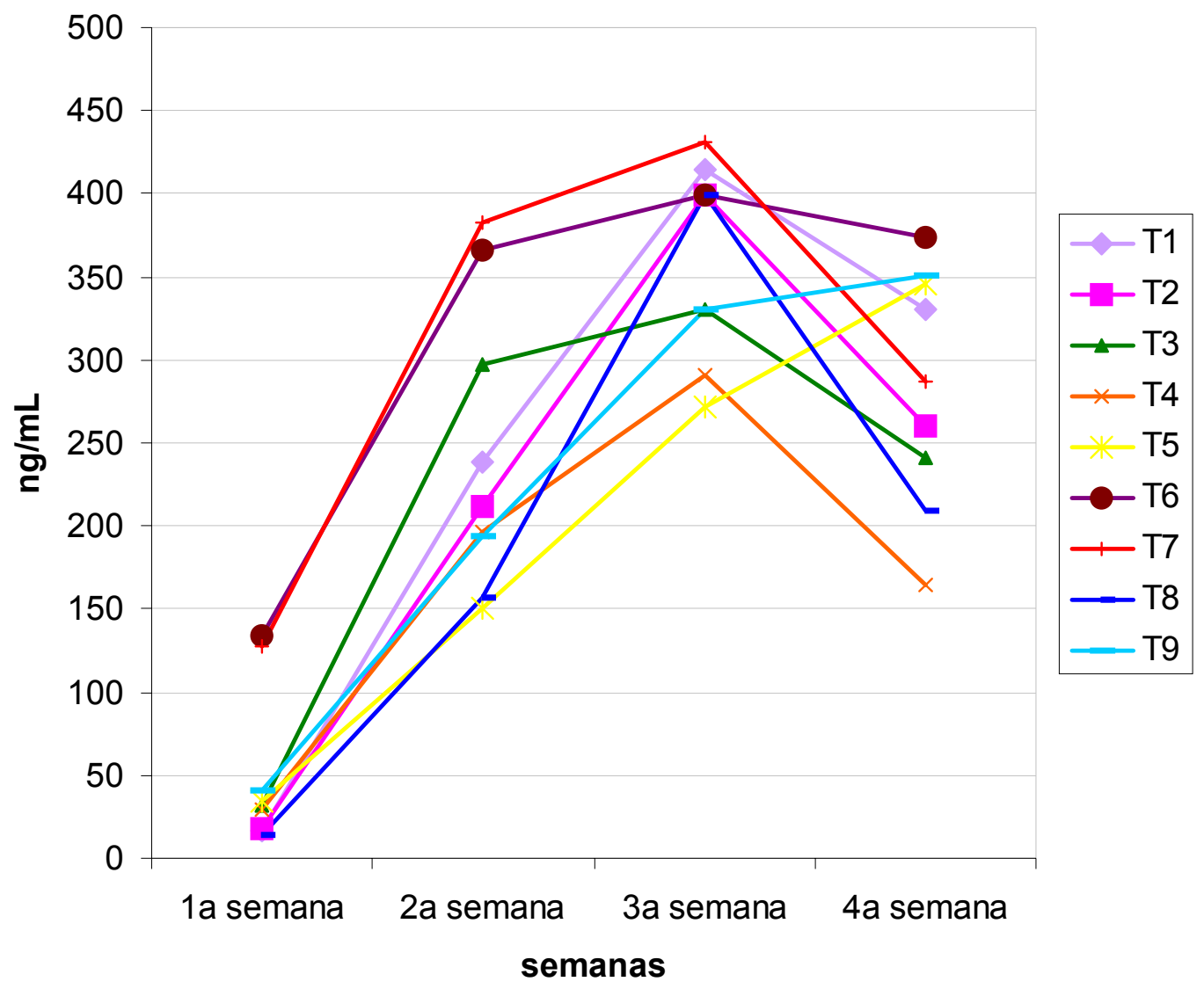


Figura 5 - Comparação das concentrações de $\operatorname{lgA}(\mathrm{ng} / \mathrm{mL})$ no soro durante todo o periodo do experimento.

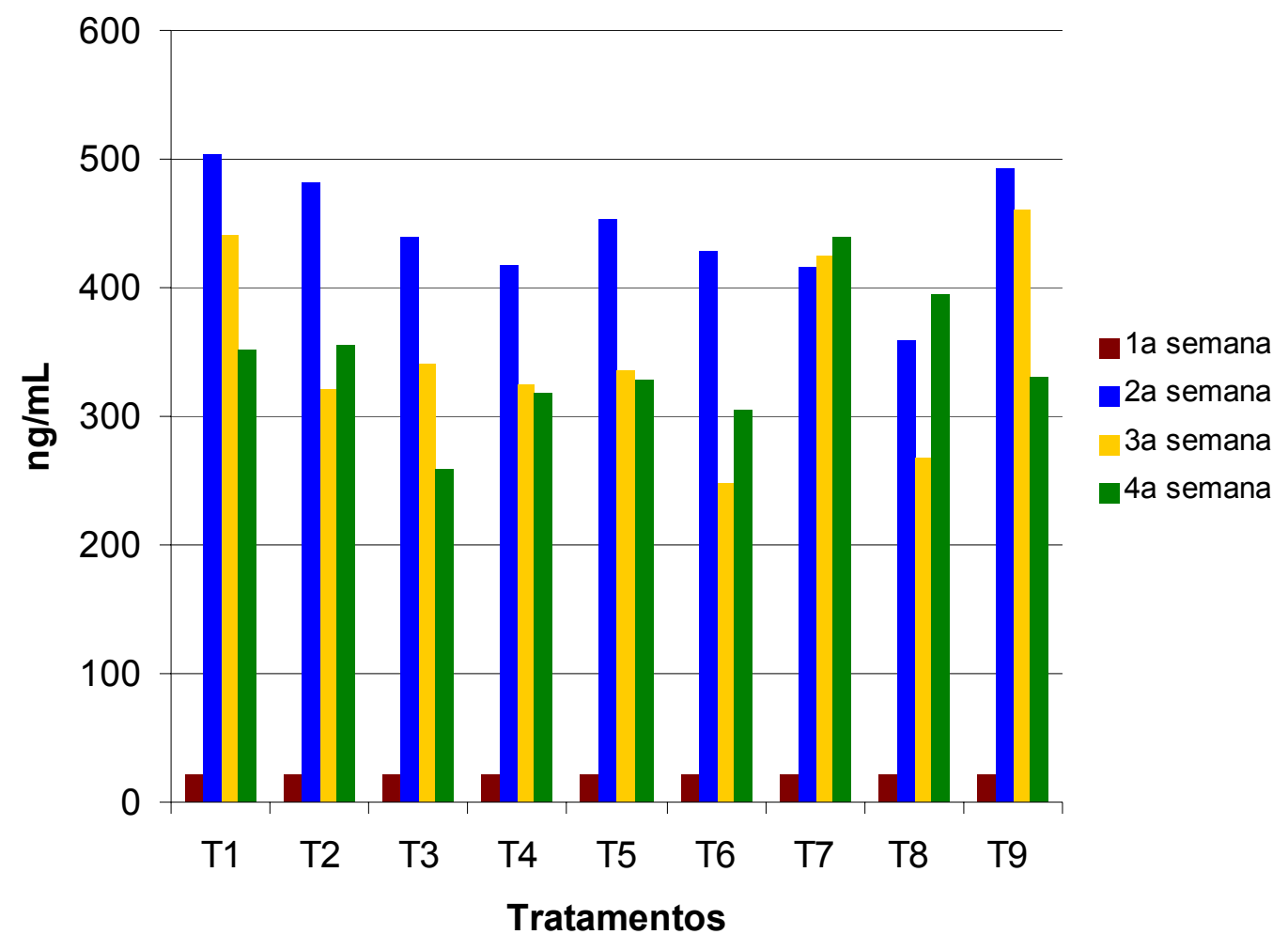


Figura 6 - Comparação das concentrações de $\lg A$ (ng/mL) no conteúdo intestinal durante todo o periodo do experimento.

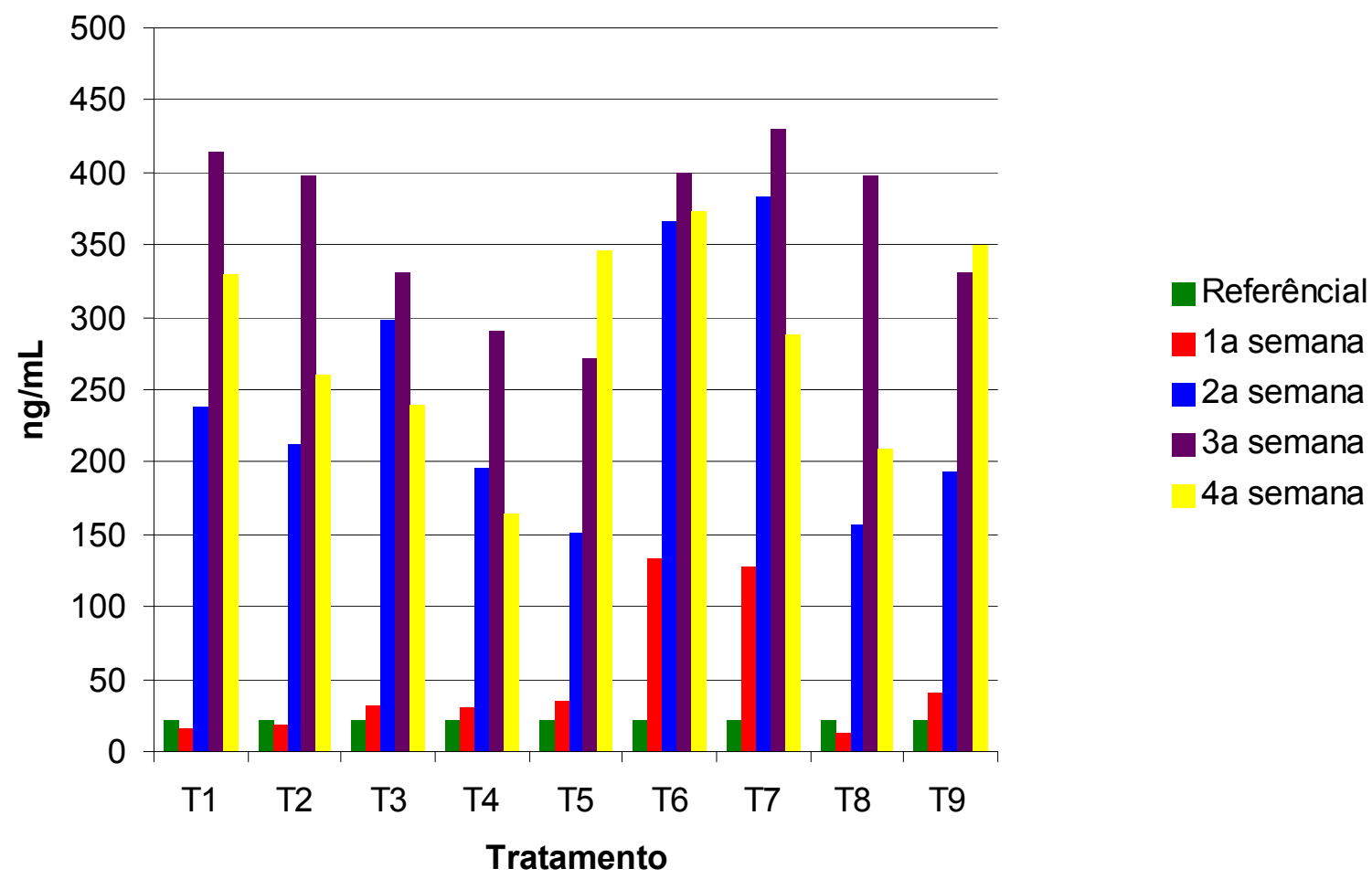


Tabela 11- Média de $\log _{10}$ UFCSalmonella/g em amostras de aves na segunda semana de idade

\begin{tabular}{ccccccc}
\hline Tratamento & \multicolumn{2}{c}{ Média $\log _{10}$ UFC Salmonella/g } & \multicolumn{3}{c}{ Positivos (positivos/total) } \\
\cline { 2 - 7 } & Ceco & Fígado & Baço & Ceco & Fígado & Baço \\
\hline T1 & $2,92^{\mathrm{c}}$ & $0,34^{\mathrm{b}}$ & $2,54^{\mathrm{c}}$ & $9 / 10$ & $3 / 10$ & $3 / 10$ \\
T2 & $2,96^{\mathrm{c}}$ & $0,19^{\mathrm{b}}$ & $0^{\mathrm{a}}$ & $6 / 10$ & $1 / 10$ & 0 \\
T3 & $3,31^{\mathrm{d}}$ & $1,00^{\mathrm{c}}$ & $1,91^{\mathrm{b}}$ & $10 / 10$ & $2 / 9$ & $1 / 9$ \\
T4 & $3,16^{\mathrm{d}}$ & $1,24^{\mathrm{c}}$ & $2,97^{\mathrm{c}}$ & $10 / 10$ & $6 / 10$ & $2 / 10$ \\
T5 & $2,23^{\mathrm{c}}$ & $0,45^{\mathrm{b}}$ & $0^{\mathrm{a}}$ & $9 / 10$ & $1 / 10$ & 0 \\
T6 & $2,49^{\mathrm{c}}$ & $0^{\mathrm{a}}$ & $0^{\mathrm{a}}$ & $9 / 10$ & 0 & 0 \\
T7 & $3,43^{\mathrm{d}}$ & $0^{\mathrm{a}}$ & $0^{\mathrm{a}}$ & $9 / 10$ & 0 & 0 \\
T8 & $0^{\mathrm{a}}$ & $0^{\mathrm{a}}$ & $0^{\mathrm{a}}$ & 0 & 0 & 0 \\
T9 & $3,63^{\mathrm{d}}$ & $1,48^{\mathrm{c}}$ & $0^{\mathrm{a}}$ & $10 / 10$ & $1 / 10$ & 0 \\
\hline
\end{tabular}


Tabela 12- Média de $\log _{10}$ UFC Salmonella/g em amostras de aves na terceira semana de idade

\begin{tabular}{|c|c|c|c|c|c|c|}
\hline \multirow[t]{2}{*}{ Tratamento } & \multicolumn{3}{|c|}{ Média $\log _{10}$ UFC Salmonella/g } & \multicolumn{3}{|c|}{ Positivos (positivos/total) } \\
\hline & Ceco & Fígado & Baço & Ceco & Fígado & Baço \\
\hline $\mathrm{T} 1$ & $0,28^{b}$ & $0^{a}$ & $0^{a}$ & $3 / 10$ & 0 & 0 \\
\hline $\mathrm{T} 2$ & $0,26^{b}$ & $0^{a}$ & $0^{a}$ & $1 / 10$ & 0 & 0 \\
\hline T3 & $0,39^{b}$ & $0,34^{b}$ & $0^{a}$ & $2 / 10$ & $1 / 10$ & 0 \\
\hline T4 & $1,22^{\mathrm{C}}$ & $0^{a}$ & $0^{a}$ & $3 / 10$ & 0 & 0 \\
\hline T5 & $0,22^{b}$ & $0^{a}$ & $0^{a}$ & $1 / 10$ & 0 & 0 \\
\hline T6 & $0,23^{b}$ & $0^{a}$ & $0^{a}$ & $1 / 10$ & 0 & 0 \\
\hline T7 & $0,96^{c}$ & $0^{a}$ & $0^{a}$ & $2 / 10$ & 0 & 0 \\
\hline T8 & $0^{a}$ & $0^{a}$ & $0^{a}$ & 0 & 0 & 0 \\
\hline T9 & $0,34^{b}$ & $0^{a}$ & $0^{a}$ & $6 / 10$ & 0 & 0 \\
\hline
\end{tabular}


Tabela 13- Média de $\log _{10}$ UFC Salmonellalg em amostras de aves na quarta semana de idade

\begin{tabular}{ccccccc}
\hline Tratamento & \multicolumn{2}{l}{ Média Log $_{10}$ UFC Salmonella/g } & \multicolumn{3}{l}{ Positivos (positivos/total) } \\
\cline { 2 - 7 } & Ceco & Fígado & Baço & Ceco & Fígado & Baço \\
\hline T1 & $0,08^{\mathrm{b}}$ & $0^{\mathrm{a}}$ & $0^{\mathrm{a}}$ & $1 / 10$ & 0 & 0 \\
T2 & $0^{\mathrm{a}}$ & $0^{\mathrm{a}}$ & $0^{\mathrm{a}}$ & 0 & 0 & 0 \\
T3 & $0^{\mathrm{a}}$ & $0^{\mathrm{a}}$ & $0^{\mathrm{a}}$ & 0 & 0 & 0 \\
T4 & $0^{\mathrm{a}}$ & $0^{\mathrm{a}}$ & $0^{\mathrm{a}}$ & 0 & 0 & 0 \\
T5 & $0^{\mathrm{a}}$ & $0^{\mathrm{a}}$ & $0^{\mathrm{a}}$ & 0 & 0 & 0 \\
T6 & $0^{\mathrm{a}}$ & $0^{\mathrm{a}}$ & $0^{\mathrm{a}}$ & 0 & 0 & 0 \\
T7 & $0^{\mathrm{a}}$ & $0^{\mathrm{a}}$ & $0^{\mathrm{a}}$ & 0 & 0 & 0 \\
T8 & $0^{\mathrm{a}}$ & $0^{\mathrm{a}}$ & $0^{\mathrm{a}}$ & 0 & 0 & 0 \\
T9 & $0,28^{\mathrm{c}}$ & $0^{\mathrm{a}}$ & $0^{\mathrm{a}}$ & $3 / 10$ & 0 & 0 \\
\hline
\end{tabular}


"Quando um patógeno está presente no trato gastrointestinal de um animal e os tecidos deste animal ou seus produtos são utilizados como fonte de alimento para os humanos, estando seu conteúdo intestinal contaminado, então o patógeno pode transmitir-se aos humanos" (SAVAGE, 1987). Salmonelas não são bactérias nativas da microbiota intestinal das aves, mas elas colonizam o intestino e permanecem durante o período de criação.

A infecção por Salmonella Typhimurium nas aves resulta em uma infecção entérica persistente sem sinais clínicos, representando uma fonte potencial de contaminação das carcaças no abatedouro e a porta de entrada na cadeia alimentar nos humanos (BEAL et al., 2004).

\section{Avaliacão da eficácia dos produtos de exclusão competitiva e suas}

\section{associações}

Diferentes métodos podem ser utilizados para aumentar a resistência das aves contra infecções por Salmonella (MEAD; BARROW, 1990). Usando os produtos de exclusão competitiva (EC), a resistência presente em aves adultas pode ser transferida a aves de um dia de idade para se obter o melhor efeito protetor (BOLDER et al., 1992). Os produtos de exclusão competitiva, desde sua primeira utilização na Finlândia em um surto de Salmonella infantis (NURMI; RANTALA, 1973), vêm demonstrando sua eficácia na inibição da colonização por Salmonella e na redução desta bactéria nos produtos avícolas (BAILEY et al., 2000; NUOTIO et al., 1992; PIVNICK et al., 1981). 
O efeito protetor destas culturas é dependente da administração de bactérias viáveis, que incluem anaeróbios, aeróbios e alguns gëneros não definidos, pois culturas aeróbias não mostraram o mesmo efeito protetor (RANTALA, 1974). A pré-exposição a Salmonella antes de um tratamento com EC pode reduzir substancialmente a proteção de culturas eficazes (BAILEY et al. 1998).

A Tabela 9 mostra a colonização e invasão nos grupos que receberam EC ou associações durante uma única semana de tratamento. Como pode ser observado, somente o grupo tratado com produto de EC mostrou colonização elevada dos cecos, em contraste com resultados obtidos com estas culturas que demonstraram a sua eficácia nos programas de controle de Salmonella (WIERUP et al., 1992). A elevada concentração bacteriana utilizada no desafio das aves, pode ter sido responsável pela ausëncia de eficiëncia neste tratamento. Por outro lado, os resultados observados neste tratamento $\mathrm{T} 1$, onde utilizou-se somente o produto de exclusão competitiva, comparam-se aos descritos por Massa et al. (1998), onde não foi observada proteção frente a um desafio com Salmonella Kedougou, e aos resultados obtidos por STRAVIC et al. (1985), onde aves tratadas com misturas contendo 50, 40, 25 e 10 isolados bacterianos mostraram resultados positivos somente naquelas aves que receberam a mistura definida com 50 espécies.

Por outro lado, os outros três tratamentos mostraram diferentes níveis de colonização. Estes continham misturas de produto EC, probióticos e/ou 
glucano e mostraram eficácia quando avaliados de acordo com o protocolo de Mead et al., (1989). A Tabela 10 mostra o fator de infectividade (IF) e o fator de proteção (PF) dos tratamentos que incluiram EC. Os resultados indicaram que a melhor resposta foi a do T6, com um PF de 14,0 (90\%). Em segundo lugar o tratamento T5, com um PF de 7,0 (80\%). Ambos grupos mostraram IF baixos e evidenciaram PF $>4$, sugerido como o valor mínimo para que um produto seja eficaz (MEAD et al., 1989). Os resultados indicaram que o tratamento contendo $\mathrm{EC}+\mathrm{LEB}+\mathrm{G}$ (T6) mostrou melhores resultados, tanto de proteção como na redução da colonização cecal.

Associados a estes resultados de proteção e redução de colonização cecal, foram avaliados os níveis de anticorpos na mucosa $(\lg A)$ em ambos os tratamentos T5 e T6 (Tabelas 9 e 10 e Figura 6), onde a concentração média de IgA no conteúdo intestinal destes grupos foi significativamente mais alta $(p<0,05)$ que a dos outros tratamentos, o que sugeriria a proteção na mucosa e a conseqüente ausência de invasão nos órgãos internos pela amostra de Salmonella Typhimurium Nal' nestes grupos.

Pode-se sugerir, ainda, que a inibição da invasão esteja relacionada aos níveis de anticorpos elevados devido à estimulação em conseqüência do tratamento com glucano, e o efeito aditivo do probiótico e glucano presentes nos tratamentos T5 e T6, respectivamente. A respeito do glucano, Acevedo et al. (2001) demonstraram sua eficácia nas aves quando aplicado oralmente, ocasião em que exerce uma estimulação na mucosa intestinal para a produção de $\lg A$. Neste estudo demonstrou-se que os valores de $\lg A$ foram 
significativamente elevados $(p<0,05)$ quando comparados com os outros tratamentos. A participação do glucano na resposta imune e no efeito sinérgico no tratamento junto ao probiótico deve ser considerada como um mecanismo de proteção das aves frente ao desafio com Salmonella Typhimurium. Isto pode ser confirmado analisando-se os valores na resposta imune no grupo controle negativo, na primeira e segunda semana pós tratamento (Tabela 10), em comparação com os grupos T3, T5, T6 e T7. Estes resultados estão de acordo com o trabalho de Tsukada et al. (2003), que afirmaram que o glucano pode ser um imunoadjuvante que estimularia a imunidade das mucosas do trato digestivo. Os glucanos são polímeros de parede celular de fungos e leveduras, e possuem atividade imunomoduladora (BROWN; GORDON, 2003). Além disso, seus efeitos biológicos na ativação e estimulação de citocinas já foram descritos (TSUKADA et al., 2003).

Finalmente, deve ser mencionado que o probiótico produzido experimentalmente neste estudo, que incluiu na sua composição Bifidobacterium bifidum, enterococos e lactobacilos, apresentou resultados positivos nas aves, especialmente naqueles grupos tratados com suas associações. Isto pode ser explicado considerando estudos que afirmam que as bifidobactérias estimulam a produção de lgA intestinal (PARK et al., 2002), os enterococos exibem efeitos de exclusão na proteção das aves contra Salmonella Typhimurium ((HUFNAGEL et al., 2003; PEREIRA; GIBSON, 2002; SOEJARDI et al., 1978), e finalmente, os lactobacilos, que demonstraram não só seu efeito protetor mas também imunomodulador e estimulante da produção de IgA (KOENEN et al., 2004; MALDONADO 
GALDEANO e PERDIGON, 2004; PERDIGON et al., 1990). Não existem dados na literatura descrevendo a associação de EC, probióticos e glucanos, ou de EC e glucanos, na redução de patógenos entéricos em aves. Os resultados obtidos neste estudo mostraram um efeito sinérgico ou aditivo destas associações. Os produtos de exclusão competitiva e os probióticos têm sido estudados na prevenção da colonização de Salmonella em aves, individualmente (PIVNICK et al., 1982) e em comparação entre eles (WATERS et al., 2005), onde foi determinado que culturas definidas de probióticos são menos eficazes que preparações geradas de microflora cecal completa.

Em aves com duas semanas de idade (Tabela 11), mostrou-se que não houve redução de colonização dos cecos nos tratamentos, porém observaram-se diferenças significativas entre os grupos, com relação às médias de $\log _{10}$ UFC Salmonella /g de 2,23 no T5 e 2,49 no T6. No entanto, no tratamento T5 houve invasão no fígado somente em uma ave (10\%), e nos tratamentos T6 e T7 não houve invasão em nenhum dos órgãos avaliados. Nos três tratamentos, o fator comum foi o glucano fornecido durante o experimento, pelo que pode-se sugerir que a associação deste produto com EC e/ou probióticos tem a capacidade de inibir ou reduzir a invasão dos órgãos, resultado similar foi obtido por Lowry et al. (2005), que demonstrou que o glucano utilizado como abiótico reduz ou inibe a colonização cecal, e a invasão dos órgãos. O tratamento 3 (Tabelas 11 e 12), onde foi administrado exclusivamente glucano, não corroborou os resultados de Lowry et al. (2005). 
Estas diferenças de resultados podem ter relação com o delineamento experimental em relação à administração de glucano e à cepa de desafio.

\section{Avaliação dos tratamentos na colonização cecal e na invasão dos órgãos}

As bactérias patogênicas possuem um processo altamente especializado que ativa sua co-participação nas funções das células epiteliais, aumentando sua penetração no epitélio intestinal do hospedeiro para causar doença (LU; WALKER, 2001). Foi descrito por Lu e Walker (2001) que Salmonella Typhimurium aumenta sua própria capacidade de ligação com a célula porque co-participa com o receptor de fosforilação da célula do hospedeiro.

Numerosos fatores afetam a colonização de Salmonella. Estes incluem a idade, a concentração e características da cepa utilizada no desafio, o estresse, a condição de saúde e a linhagem genética, entre os mais importantes. Existem sorotipos de Salmonella mais adaptados a colonizar o trato gastrointestinal das aves e com mais freqüência são isoladas dos cecos (BROWNELL et al., 1969; MILNER e SHAFFER, 1952; SNOEYENBOS et al., 1982). Existem evidências sugerindo que a colonização está diretamente relacionada às fimbrias e à motilidade mediada por flagelos (DIBB-FULLER

et al., 1999), e ainda deve considerar-se alguns genes da bactéria que estariam envolvidos neste processo (TURNER et al., 1998). Da mesma maneira, estudos realizado por Craven (1994) e Methner et al. (2004) 
confirmaram que cepas de Salmonella com mutações poderiam perder ou reduzir sua capacidade de colonização do intestino de aves.

Em relação à colonização por Salmonella em todos os grupos tratados, sugere-se que, independentemente do tratamento, na medida que a idade das aves aumenta, elas adquirem resistência para a colonização cecal, assim como, para a invasão dos órgãos por Salmonella Typhimurium. Isto tornou-se evidente quando foram avaliados os dados do grupo controle positivo (T9) onde, na primeira semana, a colonização cecal atingiu $88,8 \%$, na segunda semana $100 \%$, na terceira semana $60 \%$ e, na última semana, somente $30 \%$. Estes resultados confirmam aqueles descritos na literatura, onde se demonstrou que a susceptibilidade à infecção por via oral diminuiu rapidamente com a idade (MILNER; SHAFFER, 1952), e que a excreção reduzia gradualmente após quatro semanas quando se fazia inoculação oral (BARROW et. al. 1988).

Na terceira semana (Tabela 12), pôde observar-se uma redução da colonização cecal considerando os valores médios do $\log _{10}$ UFC Salmonella/g, assim como uma diminuição de aves positivas em todos os tratamentos. Na quarta semana (Tabela 13), todos os tratamentos foram negativos à colonização, exceto o T1 (EC), onde uma ave mostrou-se positiva, com níveis significativamente menores aos da semana anterior; mas a invasão esteve ausente em todos os tratamentos. No controle positivo, nesta mesma semana, verificou-se somente $30 \%$ das aves positivas, sem invasão dos órgãos. Estes resultados são similares aos obtidos sob condições experimentais por Sadler et al. (1969) e Smith e Tucker (1975), que 
demonstraram também uma redução da excreção de Salmonella em animais mais velhos; confirmado por BAILEY (1987), que afirma que aves jovens mostram maior susceptibilidade à colonização. Em contraste, Linton et al. (1985) observaram um aumento da infecção a partir da terceira semana, e uma diminuição após esse período.

Da mesma maneira, Lafont et al. (1983) e Beal et al. (2004), confirmaram que as aves são portadoras assintomáticas de Salmonella Typhimurium, isto foi observado tanto no grupo controle positivo como nos grupos tratados, onde se confirmou a colonização cecal e a invasão dos órgãos, sem sinais clínicos da doença após o desafio.

\section{Avaliação dos efeitos dos tratamentos sobre a resposta imune nas aves}

Antes de se avaliar os resultados da quantificação da resposta imune através da detecção de $\lg G$ e $\lg A$, e a sua participação na redução ou inibição da colonização e invasão dos orgãos, foi necessário se fazer uma breve avaliação dos valores encontrados no grupo recebido no dia 0 do experimento, tal como detalha a Tabela 4.

Os níveis séricos médios de lgG foram de $156,46 \mathrm{ng} / \mathrm{mL}$, valor que foi diminuindo gradualmente durante todo o período do experimento (Tabela 7). Estes níveis podem explicar-se pela transferência materna de anticorpos, embora os anticorpos maternos transferidos via ovo não aumentem a resistência de aves de um dia à infecção oral por Salmonella Typhimurium 
(METHNER et al., 1994). A IgG no conteúdo intestinal apresentou um valor médio de $115,12 \mathrm{ng} / \mathrm{mL}$ no dia 0 do experimento, apresentando uma diminuição drástica nas seguintes semanas (Tabela 8). Em ambos os casos, a avaliação preliminar da lgG sérica e intestinal e sua redução significativa $(p<0,05)$ durante o período do experimento sugerem que a infecção experimental com Salmonella Typhimurium, assim como, os tratamentos fornecidos junto à ração, não ativaram a produção de lgG, ao contrário dos resultados obtidos por Brito et al. (1993), que encontraram um aumento significativo no soro e mucosa intestinal uma semana após a inoculação com Salmonella Typhimurium.

Por outro lado, encontrou-se um valor médio de $21,11 \mathrm{ng} / \mathrm{mL}$ de $\lg \mathrm{A}$ sérica, verificando-se um aumento durante todas as semanas do experimento (Tabela 9), o que seria uma evidência que os tratamentos, o desafio com Salmonella e a exposição ao meio ambiente estimulariam o sistema imune das mucosas, como foi descrito por Fukutome et al. (2001). No conteúdo intestinal detectou-se uma concentração média de 368,91 ng/mL, ocorrendo na primeira semana uma considerável diminuição destes valores (Tabela 10), sugerindo que a $\operatorname{lgA}$ que é transferida à progênie não teria efeito protetor durante a primeira semana de vida das aves contra patógenos entéricos. A partir da segunda semana, observou-se um aumento dos níveis de $\lg A$ em todos os grupos tratados, quando foram comparados ao controle negativo, confirmando os resultados obtidos por Cooper et al. (1989) e Mestecky (1987), que atribuiram ao sistema imune das mucosas um papel importante 
na proteção das aves nas infecções intestinais, independente da imunidade sistêmica.

O conhecimento da estrutura e função dos tecidos linfóides nas aves e dos mecanismos imunes no trato intestinal é imprescindível, e estudos como os realizados por Jeurissen et al. (1994), Muir (1998) e Muir et al. (2000), contribuíram para esclarecer uma parte dos mecanismos na imunidade das mucosas e trato intestinal das aves. Baseado nestes estudos, é sabido que, após o nascimento das aves, a exposição ao meio ambiente é imediata e que, apesar da transferência de anticorpos maternos, não existe um mecanismo pós-nascimento nas aves, como ocorre nos mamíferos, com a absorção do colostro; dessa forma não existe em aves de um dia resistência à infecção oral por Salmonella Typhimurium (METHNER et al., 2004).

As superfícies da mucosa é a maior porta de entrada de bactérias, incluindo Salmonella, e por isso os tecidos linfóides presentes têm características especiais, limitando a aderência das bactérias ao epitélio e reduzindo a colonização (LILLEHOJ; TROUT, 1996; MESTECKY, 1987). O sistema imune das mucosas tem um papel importante na proteção dos animais às infecções intestinais e é independente da imunidade sistêmica (COOPER et al, 1989; MESTECKY, 1987). Assim, Fukutome et al., demonstraram a indução de imunidade de mucosa específica no intestino, após a imunização intraocular com um antígeno de Salmonella Enteritidis. Esta imunidade está relacionada com o GALT, que nas aves amadurece durante as primeiras duas semanas de vida. Este amadurecimento está relacionado com a dinâmica das populações de linfócitos no intestino, 
incluindo linfócitos T e células "natural killer" (NK), assim como de células B (BAR-SHIRA et al, 2003).

Com os resultados obtidos neste estudo, considerando os níveis de $\lg$ quantificados durante todo o experimento (Tabelas 7 e 8), pode ser sugerido que Salmonella Typhimurium, independente do tratamento utilizado, não produziu uma estimulação sistêmica do sistema imune, e não houve detecção siginificativa $(p<0,05)$ de IgG. Um resultado similar foi encontrado por Fukutome et al. (2001), que imunizaram aves por via oral e intraocular, e observaram uma resposta menor de lgG nas aves após a imunização oral. Com relação a IgA nos soros e conteúdo intestinal, observou-se neste estudo um aumento significativo $(p<0,05)$ durante o período do experimento (Tabelas 9 e 10) em todos os tratamentos e no controle positivo, o que sugere que os mecanismos de defesa mediados por IgA poderiam contribuir para a eliminação de Salmonella Typhimurium e pela evidência da ausência de colonização na quarta semana do experimento. Estes resultados concordam com os de Beal et al. (2004), que descreveram que a idade de exposição está relacionada diretamente com a resposta de anticorpos, e que a eliminação de Salmonella é dependente da idade, sendo que aves infectadas primariamente em idade precoce demoram mais para eliminar a bacteria que aves mais velhas, sugerindo ainda que tal comportamento poderia estar relacionado com o aumento da capacidade de resposta de células T presentes na mucosa intestinal.

As interações que ocorrem na mucosa intestinal são o resultado da relação entre os microrganismos e o hospedeiro naquele espaço. É 
conhecido que a microbiota do intestino estimula a proliferação de células epiteliais e aumenta a superfície intestinal total (HEYMAN et al., 1986), e que a colonização do intestino pela microbiota afeta o desenvolvimento do sistema imune (HAMANN et al., 1998). As Figuras 5 e 6 mostram os níveis de estimulação da IgA no soro e conteúdo intestinal em todos os grupos estudados, inclusive nos grupos controle negativo e positivo. A resposta no grupo controle positivo é similar àquela descrita por Lessard et al. (1995), que demonstraram que as funções imunes tanto humoral como celular são ativadas após a infecção por Salmonella Typhimurium, sendo que esta resposta poderia estar associada à expressão de citocinas (WHITANAGE et al., 2004) e à resposta inflamatória severa pós-infecção (WHITANAGE et al., 2005). A resposta imune positiva de $\lg A$ no grupo controle negativo, apesar das diferenças significativas com os grupos tratados e o controle positivo, pode ser explicada nas evidências científicas de que os ingredientes da dieta favorecem a resposta imune (LESHCHINSKY; KLASING, 2001) e os mecanismos de modulação nutricional podem muitas vezes ser de importância crítica na resistência às doenças infecciosas nas aves (KLASING, 1998). Estes mecanismos foram descritos por Klasing (1998) e podem ser resumidos como segue: a) a nutrição pode ter um impacto no sistema imune, porque uma deficiência de micronutrientes que participam no amadurecimento dos órgãos linfoides pode afetá-lo negativamente; b) há necessidade de nutrientes para a resposta por parte de células e a síntese de moléculas; c) a baixa concentração de alguns nutrientes nos fluídos podem limitar substratos para a proliferação ou invasão de patógenos; d) alguns nutrientes têm ação direta na regulação dos leucócitos por ligação a 
receptores intracelulares ou pela modificação da disponibilidade de segundos mensageiros; e) a dieta pode ter efeitos regulatórios indiretos associados ao sistema endócrino e f) aspectos físicos e químicos da dieta podem modificar as populações de microrganismos no trato gastrointestinal, a capacidade dos patógenos de aderir-se aos enterócitos e a integridade epitélio intestinal. Em relação aos grupos tratados, todos tiveram uma resposta positiva de IgA tanto no soro como no conteúdo intestinal, como pode observar-se nas figuras 5 e 6, embora no soro o melhor comportamento foi observado no T7 (LEB+G) e no conteúdo intestinal T6 $(E C+L E B+G)$ e T7 $(L E B+G)$; isto indica que os probióticos e o glucano associados exerceram uma ação estimulante do sistema imune das mucosas, como foi descrito para cada grupo destas substâncias, individualmente, por diferentes autores (BROWN; GORDON, 2003; LOWRY et al., 2005; PATTERSON; BURKHOLDER, 2003; PERDIGON et al., 1990). Neste estudo, os resultados sugerem que o efeito sinérgico de ambas substâncias associadas sobre a estimulação do sistema imune apresentou uma relação direta com a inibição da invasão dos órgãos nos grupos T6 e T7.

Estes resultados contribuem para o entendimento dos mecanismos que poderiam estar interagindo quando produtos de exclusão competitiva, probióticos e glucanos são administrados nas aves. Entre eles, a estimulação do sistema imune é um dos que pode ter um papel primordial na inibição da colonização por parte de bactérias patógenas. Nos probióticos, a eficácia de bactérias lácticas, um dos principais componentes do probiótico experimental testado neste experimento, pode ser influenciada pela idade, o estado 
fisiológico da ave e a qualidade e quantidade de alimento (HERICH; LEVKUT, 2002). Os dados publicados por diferentes autores (GONG et al., 2002; LU et al., 2003), demonstraram que os lactobacilos predominam no intestino delgado, e que a flora cecal é composta em sua maioria por anaeróbios e algumas bactérias facultativas. Muitos fatores podem afetar a composição da comunidade bacteriana nas aves, como a dieta (KNARREBORG et al., 2002), a idade (VAN DER WIELEN et al., 2002; ZHU et al., 2002), a administração de antibióticos (KNARREBORG et al., 2002) e a infecção com organismos patógenos (KIMURA et al., 1976).

Portanto, mudanças na composição da dieta ou na densidade dos nutrientes podem ter efeitos diretos na população da microbiota intestinal (GIBSON et al., 1996; HILMANN, 1999). Esta premissa pode ser utilizada para sustentar que as bactérias podem ser favorecidas no trato intestinal, ou que podem ser manipuladas favoravelmente, para estimular aquelas que estariam sendo administradas nos produtos de exclusão ou probióticos, com o objetivo de aumentar a capacidade benéfica. Neste sentido, Thitaram et al. (2005) demostraram que um composto derivado de fermentação chamado isomaltooligosacarídeo aumenta a população cecal de Bifidobacterium em aves de corte jovens, e que esta manipulação da dieta reduz a colonização cecal por Salmonella Typhimurium Nal' ${ }^{r}$. Apajalahti et al. (2001) demonstraram que diferentes composições de dieta favoreceram algumas bactérias no trato gastrointestinal das aves. Nas aves, a dieta e o meio ambiente afetam o status microbiano do trato gastrointestinal, onde $10 \%$ de bactérias representam espécies previamente conhecidas, 35\% representam bactérias 
previamente desconhecidas dentro de um gênero conhecido, e os $55 \%$ restantes representam gêneros totalmente desconhecidos de bactérias. (APAJALAHTI et al., 2004). Desde que as bactérias se diferenciam na preferência pelos substratos, na composição química e na estrutura do alimento, isto determina a distribuição de espécies na comunidade bacteriana no trato intestinal. Conseqüentemente, é possível mudar a comunidade microbiana para bactérias benéficas ou não, através de mudanças na dieta (APAJALAHTI et al., 2004).

As bactérias intestinais têm um papel importante na saúde através de seus efeitos na morfologia, nutrição, patogenia das doenças intestinais e resposta imune. É de conhecimento geral que a microbiota nativa protege contra a colonização dos intestinos por patógenos e estimula a resposta imune (MEAD, 2000). Por outro lado, é sabido que tanto os produtos de EC como os probióticos e os glucanos estimulam favoravelmente a imunidade intestinal através da produção local de $\lg A$, e impedem mediante este mecanismo a colonização de Salmonella no trato intestinal das aves, pelo fenômeno conhecido como "exclusão imune" (WILLIAMS; GIBBONS, 1972).

Os argumentos sobre a microbiota como uma parte importante no mecanismo de exclusão suportam a busca por novos produtos, cepas bacterianas benéficas ou associações que, como neste experimento foram avaliadas. A finalidade é proporcionar às aves um equilíbrio na microbiota intestinal, que ao mesmo tempo seja eficaz para prevenir a colonização de bactérias patógenas no intestino e sua posterior invasão nos órgãos internos, 
e que finalmente seja inócua, contribuindo com a segurança alimentar do consumidor.

Este é o primeiro estudo realizado com associações de produtos de exclusão competitiva, probióticos e glucanos, onde demonstrou-se o efeito benéfico para as aves em três aspectos específicos: a redução da colonização por Salmonella Typhimurium, a redução ou inibição da invasão nos órgãos internos das aves desafiadas, e a estimulação do sistema imune especialmente $\lg \mathrm{A}$, tanto a nível sistêmico como de mucosas.

Estudos complementares precisam ser conduzidos para investigar a estimulação das células imunocompetentes, mecanismos e mediadores que estariam envolvidos na resposta imune local, assim como ampliar o conhecimento da interação dos EC, probióticos e glucanos associados com o ecosistema gastrointestinal, formado pelo epitélio, a imunidade local e a microbiota nativa. 


\section{CONCLUSÕES}

- A aquisição de microbiota normal, sua interação com a ração, a cepa de desafio e os tratamentos utilizados, estimula a produção de lgA.

- O probiótico experimental demonstrou ser eficaz na estimulação do sistema imune, através da produção de lgA.

- Os tratamentos individuais de exclusão competitiva, probiótico e glucano, não foram eficientes na prevenção da colonização e invasão dos órgãos em aves desafiadas com uma cepa de Salmonella Typhimurium Nal'.

- Os tratamentos associados de exclusão competitiva com o probiótico experimental e/ou glucano, foram eficicientes na prevenção da colonização e na invasão dos órgãos em aves desafiadas com uma cepa de Salmonella Typhimurium Nal'.

- O glucano estimula a produção de IgA, quando associado com produtos de EC e/ou com probiótico.

- A resposta local de IgA, estimulada pelos tratamentos, contribui na proteção contra Salmonella Typhimurium Nal'.

- A IgG parece não ter um papel na proteção contra Salmonella Typhimurium $\mathrm{Nal}^{r}$ durante as duas primeiras semanas de vida das aves. 


\section{REFERÊNCIAS BIBLIOGRÁFICAS}

AABO, S.; CHRISTENSEN, J. P.; CHADFIELD, M. S.; CARSTENSEN, B.; OLSEN, J. E.; BISGAARD, M. Quantitative comparison of intestinal invasion of zoonotic serotypes of Salmonella enterica in poultry. Avian Pathology, v. 31, p. 41-47, 2002.

ACEVEDO, A. M.; PEDROSO, M.; MIRANDA, I. Efecto del tratamiento con bl-3 glucano particulado lineal por vía oral sobre la respuesta humoral a la vacuna de Newcastle en pollos. Revista Cubana de Ciencia Avícola, v. 25, p. 101-106, 2001 a.

ACEVEDO, A. M.; PEDROSO, M.; MIRANDA, I. ßI-3 glucano. Influencia sobre la inmunidad mediada por celulas en pollos jóvenes. Revista Cubana de Ciencia Avícola, v. 25, p. 107-112, 2001b.

ADLER, H. E.; DAMASSA, A. J. Effect of ingested lactobacilli on salmonella infantis and escherichia coli and on intestinal flora, pasted vents, and chick growth. Avian Diseases, v. 24, p. 868-878, 1980.

ALLRED, J. N.; WALKER, J. W.; BEAL Jr.,V. C.; GERMAINE, F. W. A survey to determine the salmonella contamination rate in livestock and poultry feeds. Journal of American Veterinary Medical Association, v. 151, p. 1857-1860, 1967.

APAJALAHTI, J.; KETTUNEN, A.; GRAHAM, H. Characteristics of the gastrointestinal microbial communities, with special reference to the chicken.

World's Poultry Science Journal, v. 60, p. 223-232, 2004.

APAJALAHTI, J.; KETTUNEN, A.; BEDFORD, M.R.; HOLBEN, W.E. Percent G+C profiling accurately reveals diet-related differences in the gastrointestinal microbial community of broiler chickens. Applied Environmental Microbiology, v. 67, p. 5656-5667, 2001.

ATLAS. R.M. Handbook of microbiological media. 2.Ed.: Boca Raton: CRC Press 1997. $1706 \mathrm{p}$.

BAILEY, J. S. Factors affecting microbial competitive exclusion in poultry. Food Technology, v. 41, p. 88-92, 1987.

BAILEY, J. S. Integrated colonization control of Salmonella in poultry. Poultry Science, v. 67, p. 928-932, 1988.

BAILEY, J. S.; BLANKENSHIP, L. C.; COX, N. A. Effect of fructoolgosaccharide on Salmonella colonization of the chicken intestine. Poultry Science, v. 70, p. 24332438, 1991.

BAILEY, J. S.; CASON, J. A.; COX, N. A. Effect of Salmonella in young chicks on competitive exclusion treatment. Poultry Science, v. 77, p. 394-399, 1998. 
BAILEY, J. S.; STERN, N. J.; COX, N. A. Commercial field trial evaluation of mucosal starter culture to reduce Salmonella incidence in processed broiler carcasses.

Journal of Food Protection, v. 63, p. 867-870, 2000.

BAR-SHIRA, E.; SKLAN, D.; FRIEDMAN, A. Establishment of immune competence in the avian Galt during the immediate post-hastch period. Developmental and Comparative Immunology, v. 27, p. 147-157, 2003.

BARROW, P. A.; SIMPSON, J. M.; LOVELL, M. A. Intestinal colonization in the chicken by food-poisoning Salmonella serotypes: microbial characteristics associated with faecal excretion. Avian Pathology, v. 17, p. 571-588, 1988.

BARROW, P. A.; TUCKER, J. F.; SIMPSON, J.M. Inhibition of colonization of the chicken alimentary tract with Salmonella typhimurium gram-negative facultatively anaerobic bactéria. Epidemiology and Infection, v. 98, p. 311-322, 1987.

BEAL, R.K.; WIGLEY, P.; POWERS, C.; HULME, S.D.; BARROW, P.A.; SMITH, A.L. Age at primery infection with Salnonella enterica serovar Typhimurium in the chicken influences persistence of infection and subsequent immunity to rechallenge. Veterinary Immunology and Immunopathology, v.100, p. 151-164, 2004.

BEAL, R.K.; POWERS, C.; WIGLEY, P.; BARROW, P.A.; SMITH, A.L. Temporal dynamics of the cellular, humoral and cytokine responses in chickens during primary and secondary infection with Salmonella enterica serovar Typhimurium. Avian Pathology, v.33, p. 25-33, 2004.

BEFUS, A. D.; Johnston, N.; LESLIE, G. A.; BIENESTOCK, J. Gut-associated lymphoid tissue in the chicken. I. Morphology, ontogeny, and some functional characteristics of Peyer's patches. Journal of Immunology. v. 125, p. 2626-2632, 1980

BENDA, V.; PETROVSKY, E.; HAMPEL, A.; KALOVA, J. Glucan stimulates the antibody response to at - dependent antigen in chickens. Acta Veterinaria Brno, v. 58, p. 345-351, 1989.

BENGMARK, S. Bactéria for optimal health. Nutrition, v. 16, p. 611-615, 2000. BERCHIERI Jr., A.; ADACHI, S. Y.; CALZADA, C. T.; PAULILLO, A. C.; ITURRINO, R. P. S.; TAVECHIO, A. T. Farinha de carne como fonte de salmonella em granja avicola. Pesquisa Veterinária Brasileira, v. 9, p. 9-12, 1989.

BERG, R. D. Indigenous intestinal microflora and host immune response. EOS Journal of Immunology and Immunopharmacolology, v. 4, p. 161-168, 1985. BERTHELOT, F.; BEAUMONT, C.; MOMPART, F.; GIRARD-SANTOSUOSSO, O.; PARDON, P.; DUCHET-SUCHAUX, M. Estimate heritability of the resistance to cecal carrier state of Salmonella enteritidis in chickens. Poultry Science, v. 77 p. 797-801, 1998.

BIRCHOFF, J. Results of ten years of testing foodstuffs of animals origin for salmonella. Veterinary Bulletin, v. 39, p. 820-822, 1969. 
BLOOM, P. D.; BOEDEKER E.C. Mucosal immune responses to intestinal bacterial pathogens. Seminar of Gastrintestinal Diseases, v. 7, p. 151-166, 1996.

BOCCIA, D.; OLIVER, C. I.; CHARLETT, A.; BENNETT, S.; ORR, H.; SARANGI, J.; STUART, J. Outbreak of a new Salmonella phage type in south west England: alternative epidemiological investigations are needed. Communicable disease and public health, v. 7, p. 339-343, 2004.

BOLDER, N. M.; VAN LITH LAJT; PUTIRULAN, F. F.; JACOBS-REITSMA, W. F.; MULDER, R. W. A. W. Prevention of colonization by Salmonella enteritidis PT4 in broilers chickens. International Journal of Food Microbiology, v. 15, p. 313-317, 1992.

BOONMAR, S.; BANGTRAKULNONTH, A.; PORNRUNANGWONG, S.; MARNRIM, M.; KANEKO, K.; OGAWA, M. Salmonella in broiler chickens in Thailand with special reference to contamination of retail meat with Salmonella enteritidis. Journal of Veterinary Medical Science, v. 60, p. 1233-1236, 1998.

BORLAND, E. D. Salmonella infection in poultry. The Veterinary Record, v. 97, p. 406-408, 1975.

BRANDTZAEG, P.; BAEKKEVOD, E. S.; FARSTAD, I. N.; JAHNSEN, F. L.; JOHANSEN, F. E.; NILSEN, E. M.; YAMANAKA, T. Regional specialization in the mucosal immune system: what happens in the microcompartments. Immunology Today, v. 20, p. 141-151, 1999.

BRASSART, D.; SCHIFFRIN, E. J. The use of probiotics to reinforce mucosal defence mechanisms. Trends in Food Science and Technology, v. 8, p. 321-326, 1997.

BRITO, J.R.; HINTON, M.; STOKES, C.R.; PEARSON, G.R. The humoral and cell mediated immune response of young chickens to Salmonella Typhimurium and $\mathrm{S}$. Kedougou. British Veterinary Journal, v. 149, p. 225-234.

BROWN, G. D.; GORDON, S. Fungal $\beta$-glucans and mammalian immunity. Immunity, v. 19, p. 311-315, 2003.

BROWNELL, J.R.; SADLER, W.W.; FANELLI, M.J. Factors influencing the intestinal infection of chickens with Salmonella typhimurium. Avian Diseases, v. 13, p. 804816, 1969.

BRYAN, F. L.; DOYLE, M. P. Health risks and consequences of Salmonella and Campylobacter jejuni in raw poultry. Journal of Food Protection, v. 58, p. 326-344, 1995.

BUMSTEAD, N.; BARROW, P. Resistance to Salmonella gallinarum, S. pullorum and S. enteritidis in inbred lines of chickens. Avian Diseases, v. 37 p. 189-193, 1993. 
CHAMBERS, J. R.; BISAILLON, J. R.; LABBÉ, Y.; POPPE, C.; LANGFORD, C. F. Salmonella prevalence in crops of Ontario and Quebec broiler chickens at slaughter. Poultry Science, v. 77 p. 1497-1501, 1998.

COOPER, G. L.; NICHOLAS, R. A. J.; BRACEWELL, C. D.; Serological and bacteriological investigations of chickens from flocks naturally infected Salmonella enteritidis. Veterinary Record, v. 125, p. 567-572, 1989.

CORRAL CARRANCEJA, J.; GONZALES TORRES, R.; LABORDA GONZALES, L. Pollos como vehiculo de transporte de Salmonella en alimentos. Revista de Sanidad e Higiene Pública, (Madr.) v. 57, p. 943-947, 1983.

CORRIER, D. E.; HINTON Jr., A.; ZIPRIN, R. L.; BEIER, R. C.; DELOACH, J. R. Effect of dietary lactose on cecal $\mathrm{pH}$, bacteriostatic volatile fatty acids, and Salmonella typhimurium colonization on broiler chicks. Avian Diseases, v. 34, p. 617-625, 1990.

CORRIER, D. E.; NISBET, D. J.; SCANLAN, C. M.; TELLEZ, G.; HARGIS, B. M.; DELOACH, J. R. Inhibition of Salmonella enteritidis cecal and organ colonization in leghorn chicks by defined culture of cecal bactéria and dietary lactose. Journal of Food Protection, v. 56, p. 377-381, 1994.

CRAVEN, S. E. Altered colonizing ability for the ceca of broiler chicks by lipopolysaccharide-deficient mutants of Salmonella Typhimurium. Avian Diseases, v. 38, p. 401-408, 1994.

CUNNINGHAM-RUNDLES, S. The effect of aging on mucosal host defense. Journal of Nutrition, Health \& Aging. v. 8, p. 20-25, 2004.

DAWKINS, H. C.; ROBERTSON, L. Salmonellas in animal feeding stuffs. Monthly Bulletin of the Ministry of Health, v. 26, p. 215-221, 1967.

DE SIMONE C. Microflora, yogurt and the immune system. International Journal of Immunotherapy, (Suppl) v. 11, p.19-23, 1986.

DIBB-FULLER, M. P.; ALLEN-VERCOE, E.; THORNS, C. J.; WOODWARD, M. J. Fimbriae- and flagella-mediated association with and invasion of cultured epithelial cells by Salmonella enteritidis. Microbiology, v. 145, p. 1023-1031, 1999.

ENGSTAD, R. E.; ROBERTSEN, B. recognition of yeast cell wall glucan by atlantic salmon (Salmon salar L.) macrophages. Developmental and Comparative Immunology, v. 17, p. 319, 1993.

ENSLEY, H. E.; TOBIAS, B.; PRETUS, H. A.; McNAMEE, R. B.; JONES, E. L.; BROWDER, I. W.; WILLIAMS, D. L. NMR spectral analysys of a water-insoluble $(1,3)-B-D-g l u c a n$ isolated from Saccharomyces cerevisiae. Carbohydrate Research, v. 258 , p. 307-311, 1994. 
ETHELBERG, S.; LISBY, M.; TORPDAHL, M.; SORENSEN, G.; NEIMANN, J.; RASMUSSEN, P.; BANG, S.; STAMER, U.; HANSSON, H. B.; NYGARD, K.; BAGGESEN, D. L.; NIELSEN, E. M.; MOLBAK, K.; HELMS, M. Prolonged restaurant-associated outbreak of multidrug-resistant Salmonella Typhimurium among patients from several European countries. Clinical Microbiology Infection, v. 10, p. $904-910,2004$.

FANELLI, M. J.; SADLER, W. W.; FRANTI, C. E.; BROWNELL, J. R. Localization of Salmonellae within the intestinal tract of chickens. Avian Diseases, v. 15, p. 366375, 1971.

FERREIRA, A. J. P.; FERREIRA, C. A.; PETRELLA NETO, R; OLIVEIRA, D. R.; NUREMBERGER JÚNIOR, R.; LOPES, V. C. B. A. Probiotics: benefits and efficiency in poultry production. Arquivos do Instituto Biológico, v. 65, p. 139-149, 1998.

FUKATA, T.; SASAI, K.; MIYAMOTO, T.; BABA, E. Inhibitory effects of competitive exclusion and fructooligosaccharide, singly and in combination, on Salmonella colonization of chicks. Journal of Food Protection, v. 62, p. 229-233, 1999.

FUKUTOME, K.; WATARAI, S.; MUKAMOTO, M.; KODAMA, H. Intestinal mucosal immune response in chickens following intraocular immunization with liposomeassociated Salmonella enterica serovar enteritidis antigen. Developmental and comparative immunology, v. 25, p. 475-484, 2001.

FULLER, R. Ecological studies on the lactobacillus flora associated with the crop epithelium of the fowl. Journal of Applied Bacteriology, v. 36, p. 131-139, 1973.

FULLER, R. Probiotics foods - current use and future developments. International Food Ingredients, v. 3, p. 23-26, 1993.

GIBSON, G.R.; WILLEMS, A.; READING, S.; COLLINS, M.D. Fermentation of nondigestible oligosaccharides by human colonic bacteria. Proceedings of Nutritional Society, v. 55, p. 899-912, 1996.

GIORGI, W.; OHASHI, K.; ARAUJO, W. P. Farinha de carne e farinha de peixe como fontes de Salmonellas para animais. Arquivos do instituto Biológico. v. 38, p. 5962, 1971.

GONG, J.; FORSTER, R. J.; YU, H.; CHAMBERS, J. R.; WHEATCRAFT, R.; CHEN, S. Diversity and phylogenetic analysis of bacteria in the mucosa of chiken ceca ans comparison with bacteria in the cecal lumen. FEMS Microbiological Letters, v. 208, p. 1-7, 2002.

HACKING, W. C.; MITCHELL, W. R.; CARLSON, H. C. Salmonella investigation in an Ontario feed mill. Canadian Journal of Comparative Medicine, v. 42, p. 400406, 1978.

HAMANN, L.; EL-SAMALOUTI, V.; ULMER, A.J.; FLAND, H.D.; RIETSCHEL, E.Th. Components of gut bacteria as immunomodulators. International Journal of Foof Microbiology, v. 41, p. 141-154, 1998. 
HANG'OMBE, B. M.; SHARMA, R. M.; SKJERVE, E.; TUCHILI, L. M. Ocurrence of Salmonella enteritidis in pooled table eggs and market-ready chicken carcasses in Zambia. Avian Diseases, v. 43, p. 597-599, 1999.

HASHIMOTO, K.; SUZUKI, I; YADOMAE, T. Oral administration of SSG, A B- glucan obtained from Sclerotinia sclerotiorum, affects the function of Peyer's patch cells. International Journal of immunopharmacology, v. 13, p. 437-442, 1991.

HERICH, R.; LEVKUT, M. Lactic acid bactéria, probiotics and immune system. Veterinary Medicine, v. 47, p. 169-180, 2002.

HEYMAN, M.; CRAIN DENOYELLE, A. M.; CORTHIER, G.; MORGAT, J. L.; DESJEUX, J. F. Postnatal development of protein absorption in conventional and germ-free mice. American Journal of Physiology, v. 251, p. 326-331, 1986.

HILLMAN, K. Manipulation of the intestinal microflora for improved health and growth in pigs. Proceedings WPSA Spring Meeting, Scarborough 22-24 March, p. 56-61, 1999.

HINTON, M.; LINTON, A. H. Control of salmonella infections in broiler chickens by the acid treatment of their feed. Veterinary Record, v. 123, p. 416-421, 1988.

HINTON, M.; THRELFALL, E. J.; ROWE, B. The invasive potential of Salmonella enteritidis phage types of young chickens. Letters in Applied Microbiology, v. 10, p. 237-239, 1990.

HOLLISTER, A. G.; CORRIER, D. E.; NISBET, D. J.; BEIER, R. C.; DELOACH, J. R. Effect of lyophilization in sucrose plus dextran and rehydration in thioglycolate broth on performance of competitive exclusion cultures in broiler chicks. Poultry Science, v. 74, p. $586-590,1995$.

HUFNAGEL, M.; KOCH, S.; KROPEC, A.; HUEBNER, J. Oposibiogagicytic assay as a potentially useful tool for assessing safety of enterococcal preparations.

International Journal of Food Microbiology, v. 88, p. 263-267, 2003.

HUMPHREY, T. J.; LANNING, D. G. The vertical transmission of salmonellas and formic acid treatment of chicken feed. Epidemiology and Infection, v. 100 p. 43-49, 1988.

HUSBAND, A. J. Mucosal memory - maintenance and recruitment. Veterinary Immunology and Immunopathology, v. 87, p. 131-136, 2002.

ISA, J. M.; BOYCOT, B. R.; BROUGHTON, E. A survey of Salmonella contamination in animal feeds and feeds constituents. Canadian Veterinary Journal, v. 4, p. 4143, 1983. 
ISAACS, S.; ARAMINI, J.; CIEBIN, B.; FARRAR, J. A.; AHMED, R.; MIDDLETON, D.; CHANDRAN, A. U.; HARRIS, L. J.; HOWES, M.; CHAN, E.; PICHETTE, A. S.; CAMPBELL, K.; GUPTA, A.; LIOR, L, Y,; PEARCE, M.; CLARCK, C.; RODGERS, F.; JAMIESON, F.; BROPHY, I.; ELLIS, A. An international outbreak of salmonellosis associated eith raw almonds contaminated with a rare phage type of Salmonella enteritidis. Journal of Food Protection, v. 68, p. 191-198, 2005.

JEURISSEN, S. H. M; VERVELDE, L.; JANSE, E. M. Structure and function of lymphoid tissues of the chicken. Poultry Science, v. 5, p. 183-207, 1994.

KARAOGLU, M.; DURDAG, $\mathrm{H}$. The influence of dietary probiotics (Saccharomyces cerevisiae) Supplementation and different slaughter age on the performance, slaughter and carcass properties of broilers. International Journal of Poultry Science, v. 4, p. 309-316, 2005.

KATAOKA, K.; MUTA, T.; YAMAZAKI, S.; TAKESHIGE, K. Activation of macrophages by linear $(1 \rightarrow 3)$ - $\beta$-glucans. Implications for the recognition of fungi by innate immunity. The Journal of Biological Chemistry, v. 277, p. 36825-36831, 2002

KELLY, C. G.; YOUNSON, J. S. Anti-adhesive strategies in the prevention of infectious disease at mucosal surfaces. Expert Opinion Investigational Drugs v. 9, p. 1711-1721, 2000.

KIMURA, N.F.; MIMURA, S.; NISHIDA, S.; KOBAYASHI, A. Studies on the relationship between intestinal flora and cdcal coccidiosis in chicken. Poultry Science, v. 55, p. 1375-1383, 1976.

KLASING, K.C. Nutritional modulation of resistance to infectious diseases. Poultry Science, v. 77, p. 1119-1125, 1998.

KLUPSCH, V. H. J. Man and microflora. North European Dairy Journal, v. 51, p. 221-226. 1985.

KNARREBORG, A.; SIMON, M.A.; ENGBERG, M.; JENSEN, B.B.; TANNOCK, G.W. effects of dietary fat source and subtherapeutic levels of antibiotic on the bacterial community in the ileum of broiler chickens at various ages. Applied and

Environmental Microbiology, v. 68, p. 5918-5924, 2002.

KOENEN, M. E.; KRAMER, J.; VAN DER HULST, R.; HERES, L.; JEURISSEN, S. H.; BOERSMA, W. J. Immunomodulation by probiotic lactobacilli in layer - and metatype chickens. British Poultry Science, v. 45, p. 355-366, 2004.

KVENBERG, J. E.; ARCHER, S. L. Economic impact of colonization control on foodborne disease. Food Technology, v. 41, p. 77-88, 1987.

LAFONT, J. P.; BRÉE, A.; NACIRI, M.; YVORÉ, P.; GUILLOT, J. F.; CHASLUSDANCLA, E. Experimental study of some factors limiting "competitive exclusion" of Salmonella in chickens. Research in Veterinary Science, v. 34, p. 16-20, 1983. 
LAMONT, S. J. Impact of genetics on disease resistance. Poultry Science, v. 77, p. 1111-1118, 1998.

LEME, I.L. Avaliação de perfil de suscetibilidade a antibióticos em amostras de enterococos de origem aviária em São Paulo. 1998. 128 f. Tese (Doutorado) Escola Paulista de Medicina, Universidade Federal de São Paulo, São Paulo. 1998.

LESHCHINSKY, T.V.; KLASING, K.C. Relationship between the level of dietary vitamin $E$ and the immune response of broiler chickens. Poultry Science, v. 80, p. 1590-1599, 2001.

LESSARD, M.; HUTCHINGS, D.L.; SPENCER, J.L. Cell-mediated and humoral immune responses in chickens infected with Salmonella typhimurium. Avian Diseases, v. 39, p. 230-238, 1995.

LILLEHOJ, H. S.; TROUT, J.M. Avian gut-associated lymphoid tissues and intestinal immune responses to eimeria parasites. Clinical Microbiology Reviews, v. 9, p. 349-360, 1996.

LILLY, D.; STILLWELL, R. H. Probiotics growth - promoting factors produced by microrganisms. Science,. v. 147, p. 747-748, 1965.

LINTON, A.H.; AL-CHALABY, Z.A.; HINTON, M.H. Natural subclinical salmonella infection in chickens: a potential model for testing effects of various procedures on salmonella shedding. Veterinary Record, v. 116, p. 361-364, 1985.

LISTER, S.A. Salmonella enteritis in broilers and broiler breeders. Veterinary Record, v. 123, p. 350, 1988.

LLOYD, A. B.; CUMMING, R. B.; KENT, R. D. Prevention of Salmonella typhimurium infection in poultry by pretreatment of chickens and poults with intestinal extracts. Australian Veterinary Journal, v. 53, p. 82-87, 1977.

LOWRY, V. K.; FARNELL, M. B.; FERRO, P. J.; SWAGGERTY, C. L.; BAHL, A.; KOGUT, M. H. Purified $\beta$-glucan as an abiotic feed additive up-regulates the innate immune response in immature chickens agains Salmonella enterica serovar enteritidis. International Journal of Food Microbiology, v. 98, p. 309-318, 2005.

LU, L.; WALKER, W. A. Pathologic and physiologic interactions of bacteria with the gastrointestinal epithelium. American Journal of Clinical Nutrition, v. 73(supl.), p. 1124S-1130S, 2001.

LU, J.; IDRIS, U.; HARMON, B. HOFACRE, C.; MAURER, J. J.; LEE, M. D. Diversity and succession of the intestinal bactérial community of the maturing broiler chicken. Applied and Environmental Microbiology, v. 69, p. 6816-6824, 2003.

MADARA, J. L. The chameleon within: improving antigen delivery. Science, v. 277, p.910-911, 1997. 
MALDONADO GALDEANO, C.; PERDIGON, G. Role of viability of probiotic strains in their persistence in the gut and in mucosal immune stimulation. Journal of

Applied Microbiolology, v. 97, p.673-681, 2004.

MANNING, J. G.; HARGIS, B. M.; HINTON JR., A.; CORPIER, D. E.; DELOACH, J. R.; CREGER, C. R. Effect of selected antibiotics and anticoccidials on Salmonella enteritidis cecal colonization and organ invasion in leghom chicks. Avian Diseases, v. 38, p. 256-261, 1994.

MASSA, S.; SARRA, P. G.; CANGANELLA, F.; TROVATELLI, L. D. Protection of young chicks against Salmonella kedougou by administration of intestinal microflora. International Journal of Food Microbiology, v. 40, p. 123-126, 1998.

MAZUREK, J.; SALEHI, E.; PROPES, D.; HOLT, J.; BANNERMAN, T.; NICHOLSON, L. M.; BUNDESEN, M.; DUFFY, R.; MOOLENAAR, R. L. A multistate outbreak of Salmonella enterica serotype typhimurium infection linked to raw milk consumption - Ohio, 2003. Journal of Food Protection, v. 67, p. 2165-2170, 2004.

McGARR, C.; MITCHELL, W. R.; CARLSON, H. C.; FISH, N. A. An epidemiological study of Salmonellae in broiler chicken production. Canadian Journal of Public Health, v. 71, p. 47-57, 1980.

McHAN, F.; COX, N. A.; BLANKENSHIP, L.C.; BAILEY, S. In vitro attachment of Salmonella typhimurium to chick ceca exposed to selected carbohydrates. Avian Diseases, v. 33, p. 340-344, 1989.

MEAD, G. C. Prospects for competitive exclusion treatment to control salmonellas and other foodborne pathogens in poultry. Veterinary Journal, v. 159, p. 111-123, 2000.

MEAD, G. C.; BARROW, P. A. A Review: Salmonella control in poultry by 'competitive exclusion' or immunization. Letters in Applied Microbiology, v. 10, p. 221-227, 1990.

MEAD, G. C.; BARROW, P. A; HINTON, M. H.; HUMBERT, F.; IMPEY, C.; LAHELLEC, C.; MULDER, R. W. A.; STAVRIC, S.; STERN, N. J. Recommended assay for treatment of chicks to prevent Salmonella colonization by 'Competitive Exclusion'. Journal of Food Protection, v. 52, p. 500-502, 1989.

MESTECKY, J. The common mucosal immune system and current strategies for induction of immune responses in external secretions. Journal of Clinical Immunology, v. 7, p. 265-276, 1987.

METHNER, U.; BARROW, P. A.; GREGOROVA, D.; RYCHLIK, I. Intestinal colonization-inhibition and virulence of Salmonella phoP, rpoS and ompC deletion mutants in chickens. Veterinary Microbiology, v. 98, p. 37-43, 2004. 
METHNER, U.; BARROW, P. A.; BERNDT, A.; STEINBACH, G. Combination of vaccination and competitive exclusion to prevent Salmonella colonization in chickens: experimental studies. International Journal of Food Microbiology, v. 49, p. 35-42, 1999.

METHNER, U.; STEINBACH, G.; MEYER, H. The effectiveness of Salmonella immunization of broiler breeders on the Salmonella colonization of the animals and their progeny after experimental oral infection. Berliner and Munchener tierarztliche Wochenschrift, v.107, p. 192-198, 1994.

MILNER, K. C.; SHAFFER, M. F.; Bacteriologic studies of experimental Salmonella infections in chicks. Journal of Infectious Diseases, v. 90, p. 81-96, 1952.

MOORE, P. R.; EVENSON, A.; LUCKEY, T. D. Use of sulfasuxidine, streptothricine and streptomycine in nutritional studies with the chick. Journal Biol. Chem., v. 165, p. 437-441, 1946.

MUIR, W. I. Avian intestinal immunity: basic mechanisms and vaccine design. Poultry and Avian Biology Reviews, v. 9, p. 87-106, 1998.

MUIR, W. I.; BRYDEN, W. L.; HUSBAND, A. J. Immunity, vaccination and the avian intestinal tract. Developmental and Comparative Immunology, v. 24, p.325-342, 2000.

NAUTA, M. J.; VAN DE GIESSEN, A. W.; HENKEN, A. M. A model for evaluating intervention strategies to control salmonella in the poutry meat production chain. Epidemiology and Infection, v. 124, p. 265-373, 2000.

NUOTIO, L.; SCHNEITZ, C.; HALONEN, U.; NURMI, E. Use of competitive exclusion to protect newly-hatched chicks against intestinal colonization and invasion by Salmonella enteritidis PT4. British Poultry Science, v. 33, p. 775-779, 1992.

NURMI, E.; RANTALA, M. New aspects of Salmonella infection in broiler production. Nature, v. 247 p. 210-211, 1973.

OUWEHAND, A. C.; KIRJAVAINEN, P. V.; SHORTT, C.; SALMINEN, S. Probiotics: mechanisms and established effects. International Dairy Journal, v. 9, p. 43-52, 1999.

OYOFO, B. A.; DELOACH, J. R.; CORRIER, D. E.; NORMAN, J. O.; ZIPRIN, R. L.; MOLLENHAUER, H. H. Effect of carbohydrates on Salmonella typhimurium colonization in broiler chickens. Avian Diseases, v. 33, p. 531-534, 1989.

PAÇO, R. S. Isolamento e Identificação de Bacillus sp e Lactobacillus sp. em camas de frangos e a detecção de atividade antimicrobiana, enzimática e o crescimiento na presença de sais biliares. 2001. 66f. Dissertação (Mestrado em Ciências) - Faculdade de Medicina Veterinária e Zootecnia, Universidade de São Paulo, São Paulo. 2001. 
PADRON, M. Salmonella typhimurim outbreak in broiler chicken flocks in Mexico. Avian Diseases, v. 34, p. 221-223, 1990.

PARRY, S. M.; ALLEN, W. D.; PORTER, P. Intestinal immune response to E. coli antigens in germ-free chicken. Immunology v. 32, p. 731-741, 1977.

PARK, J.H, UM, J.U; LEE, B.J.; GOH, J.H.; PARK, S.Y.; KIM, W.S.; KIM, P.H. Encapsulated Bifidobacterium bifidum potentiates intestinal IgA production. Cellular Immunology, v. 219, p. 22-27, 2002.

PATTERSON, J. A.; BURKHOLDER, K. M. Application of probiotics and probiotics in poultry production. Poultry Science, v. 82, p. 627-631, 2003.

PERDIGON, G.; ALVAREZ, S.; NADER DE MAVCIAS, M. E.; ROUX, M. E.; PESCE DE RUIZ HOLGADO, A. The oral administration of lactic acid bactéria increase the mucosal intestinal immunity in response to enteropathogens. Journal of Food Protection, v. 53, p. 404-410, 1990.

PEREIRA, D. I.; GIBSON, G. R. Effects of consumption of probiotics and prebiotics on serum lipid levels in humans. Critical Reviews in Biochemistry and Molecular Biology, v. 37, p. 259-281, 2002.

PERSSON, U.; JENDTEG, S. The economic impact of poultry-borne salmonellosis: how much should be spent on prophylaxis? International Journal of Food Microbiology, v. 15, p. 207-213, 1992.

PIVNICK, H.; BLANCHFIELD, B.; D'AOUST, J. Y. Prevention of Salmonella infection in chicks by treatment with fecal cultures from mature chickens (Nurmi Cultures). Journal of Food Protection, v. 44, p. 909-916, 1981.

PIVNICK, H.; BLANCHFIELD, B.; RIGBY, C.; ORMSBY, E. Comparison of fresh feces with lyophilized and frozen cultures of feces as inocula to prevent Salmonella infection in chicks. Journal of Food Protection, v. 45, p. 1188-1194, 1982.

POPPE, C.; IRWIN, R. J.; FORSBERG, C. M.; CLARKE, R. C.; OGGEL, J. The prevalence of Salmonella enteritidis and other Salmonella spp. among Canadian registered commercial layer flocks. Epidemiology and Infection, v. 106, p. 259-270, 1991.

POWELL, P. C. Immune mechanisms in infection of poultry. Veterinary Immunology and Immunopathology v. 15, p. 87-113, 1987.

QIN, Z. R.; FUKATA, T.; BABA, E.; ARAKAWA A. Effect of lactose and Lactobacillus acidophilus on the colonization of Salmonella enteritidis in chicks concurrently infected with Eimeria tenella. Avian Diseases, v. 39, p. 548-553, 1995.

RAMPLING, A.; UPSON, R.; WARD, L. R.; ANDRESON, J. R.; PETERS, E.; ROWE, B. Salmonella enteritidis phage type 4 infection of broiler chickens: a hazard to public health. The Lancet, p. 436-438, 1989. 
RANTALA, M. Cultivation of a bactérial flora able to prevent the colonization of Salmonella infantis in the intestines of broiler chickens and its use. Acta Pathologica Microbiologica Section B, v. 82 p. 75-80, 1974.

REID, G.; McGROARTY, J. A.; ANGOTTI, R.; COOK, R. L. Lactobacillus inhibitor production against Escherichia coli and coaggregation ability with uropathogens. Canadian Journal of Microbiology, v. 34, p. 130-134, 1988.

ROBERTS, J. A.; SOCKETT, P. N. The socio-economic impact of human Salmonella enteritidis infection. International Journal of Food Microbiology, v. 21, p. 117-129, 1994.

SADLER, W.W.; BROWNELL, J. R.; FANELLI, M. J. Influence of age and inoculum level on shed pattern of Salmonella typhimurium in chickens. Avian Diseases, v. 13, p. 793-803, 1969.

SAHOO, P. K.; MUKHERJEE, S. C. Effect of dietary beta-1,3 glucan on immune responses and disease resistance of healthy and aflatoxin B1-induced immunocompromised rohu (Labeo rohita Hamilton). Fish Shellfish Immunol, v. 11, p. 683-695, 2001.

SAVAGE, D.C. Microorganisms associated with epithelial surfaces and stability of the indigenous gastrointestinal microflora. Die Nahrung, v. 31, p. 383-395, 1987.

SCANLAN, C. M. Current concepts of competitive exclusion cultures for the control of salmonellae in domestic poultry. Advances in Experimental Medical Biology, v. 412, p. 421-426, 1997.

SEUNA, E. Sensitivity of young chicks to Salmonella tyhimurium var. copenhagen and $S$. infantis infection and the preventive effect of cultured intestinal microflora. Avian Diseases, v. 23, p. 392-400, 1979.

SHERWOOD, E. R.; VARMA, T. K.; FRAM, R. Y.; LIN, C. Y.; KOUTROUVELIS, A. P.; TOLIVER-KINSKY, T. E. Glucan phosphate potentiates endotoxin-induced interferon-gamma expression in immunocompetent mice, but attenuates induction of endotoxin tolerance. Clinical Science, v. 101, p. 541-550, 2001.

SILLIKER, J. H. Status of Salmonella: ten years later. Journal of Food Protection. V. 43, p. 307-313, 1980.

SIMMONS, G. C. Salmonella in chickens carcasses. Australian Veterinary Journal, v. 44 , p. $40,1968$.

SMITH, H.W.; TUCKER, J.F. The virulence of Salmonella strains for chickens; their excretion by infected chickens. Journal of Hygiene, (Cambridge). V. 84, p. 479-488, 1980.

SMITH, H. W.; HALLS, S. The production of oedema disease and diarrhoea in weaned pigs by the oral administration of Escherichia coli: factors that influence the 
course of the experimental disease. Journal of Medical Microbiology, v. 1, p. 45$59,1968$.

SMYSER, C. F.; BACHARZ, J.; VAN ROEKEL, H. Detection os Salmonella typhimurium from artificially contaminated poultry feed and animal by-products. Avian Diseases, v. 7, p. 423-434, 1963.

SNOEYENBOS, G. H.; SOERJADI, A.S.; WEINACK, O. M. Gastrointestinal colonization by Salmonellae and pathogenic Escherichia coli in monoxenic chicks and poults. Avian Diseases, v. 26, p. 566-575, 1982.

SNOEYENBOS, G. H.; WEINACK, O. M.; SMYSER, C. F. Further studies on competitive exclusion for controlling salmonellae in chickens. Avian Diseases, v. 23, p. 904-914, 1979.

SOEJARDI, A. S.; RUFNER, R.; SNOEYENBOS, G. H.; WEINACK, O. M. Adherence of Salmonellae and native gut microflora to the gastrointestinal mucosa of chicks.

Avian Diseases, v. 26, p. 576-584, 1982.

SOEJARDI, A. S,; STEHMAN, S. M.; SNOEYENBOS, G. H.; WEINACK, O. M.; SMYSER, C. F. Some measurements of protection against paratyphoid Salmonella and Escherichia coli by competitive exclusion in chickens. Avian Diseases, v. 25, p. 706-712, $1981 \mathrm{a}$.

SOEJARDI, A. S,; STEHMAN, S. M.; SNOEYENBOS, G. H.; WEINACK, O. M.; SMYSER, C. F.The influence of lactobacilli on the competitive exclusion of paratyphoid salmonellae in chickens. Avian Diseases, v. 25, p. 1027-1033, 1981b.

SOEJARDI, A. S.; LLOYD, A. B.; CUMMING, R. B. Streptococcus faecalis, a bacterial isolate which protects young chickens from enteric invasion by Salmonella. Australian Veterinary Journal, v. 54, p. 549-550, 1978.

SPIEGEL, M.R. Estatística. 3a. Edicão. São Paulo: Makron Books do Brasil Editora Ltda. 1993. $646 \mathrm{p}$.

STAVRIC, S. Microbial colonization control of chicken intestine using defined cultures. Food Technology, v. 41, p. 93-98, 1987.

STRAVIC, S. GLEESON, T. M.; BLANCHFIELD, B.; PIVNICK, H. Competitive exclusion of Salmonella from newly hatched chicks by mixtures of pure bactérial cultures isolated from fecal and cecal contens of adult birds. Journal of Food Protection, v. 48, p. 778-782, 1985.

STOTT, J. A.; HODGSON, J. E.; CHANEY, J. C. Incidence of salmonellae in animal feed and the effect of pelleting on content fo enterobactériaceae. Journal of Applied Bacteriology, v. 39, p. 41-46, 1975.

SUZUKI, S. Pathogenicity of Salmonella enteritidis in poultry. International Journal of Food Microbiology, v. 21, p. 89-105, 1994. 
TANSEL, O.; EKUKLU, G.; OTKUN, M.; OTKUN, M. T.; AKATA, F.; TUGRUL, M. A food-borne outbreak caused by Salmonella enteritidis. Yonsei Medical Journal, v. 44, p. 198-202, 2003.

THITARAM, S.N.; CHUNG, C.H.; DAY, D.F.; HINTON, A. Jr.; BAILEY, J.S.; SIRAGUSA, G.R. Isomaltooligosaccharide increases cecal Bifidobacterium population in young broiler chickens. Poultry Science, v. 84, p. 998-1003, 2005.

TSUKADA, C.; YOKOYAMA, H.; MIYAJI, C.; ISHIMOTO, Y.; KAWAMURA, H.; ABO, T. Immunopotentiation of intraepithelial lymphocytes in the intestine by oral administrations of $\beta$-glucan. Cellular Immunology, v. 221, p. 1-5, 2003.

TURNER, A. K.; LOVELL, M. A.; HULME, S. D.; ZHANG-BARBER, L.; BARROW, P. A. Identification of Salmonella typhimurium genes required for colonization of the chicken alimentary tract and for virulence in newly hatched chicks. Infection and Immunity, v. 66, p. 2099-2106, 1998.

UZZAU, S.; BROWN, D. J.; WALLIS, T.; RUBINO, S.; LEORI, G.; BERNARD, S.; CASADESUS, J.; PLATT, D. J.; OLSEN, J. E. Host adapted serotypes of Salmonella enterica. Epidemiology and Infection, v. 125, p. 229-255, 2000.

VAN DER WIELEN, P.W.; KEUZENKAMP, D.A.; LIPMAN, L.J.; VAN KNAPEN, F.; BIESTERVELD, S. Spatial and temporal variation of the intestinal bacterial community in commercially raised broiler chickens during growth. Microbial Ecology, v. 44, p. 286-293, 2002.

VAUGHN, J. B.; WILLIAMS Jr., L. P.; LeBLANC, D. R.; HELSDON, H. L.; TAYLOR, C. Salmonella in a modern broiler operation: a longitudinal study. American Journal of Veterinary Research, v. 35, p.737-741, 1974.

VOLTERRA, V. Variations and fluctuations of the number of individuals in an animal species living together. Journal Conseil International pour I'Exploration de la Mer v. 3, p. 3, 1928.

WATERS, S. M.; MURPHY, R. A.; POWER, R. F. G. Assessment of the effects of nurmi-type cultures and a defined probiotics preparation on a Salmonella Typhimurium 29E challenge in vivo. Journal of Food Protection, v. 68 p. 12221227, 2005.

WEINACK, O. M.; SNOEYENBOS, G. H.; SOEJARDI-LIEM, A. S.; SMYSER, C. F. Influence of temperature, social, and dietary stress on development and stability to protective microflora in chickens against S. typhimurium. Avian Diseases, v. 29, p. 1177-1183, 1985.

WEIR, D. M.; BLACKWELL, C. C. Interaction of bacteria with the immune system. Journal of Clinical Immunolology v. 10, p. 1-2, 1983. 
WHITANAGE, G.S.; WIGLEY, P.; KAISER, P.; MASTROENI, P.; BROOKS, H.; POWERS, C.; BEAL, R.; BARROW, P.; MASKELL, D.; McCONELL, I. Cytokine and chemokine responses associated with clearance of a primary Salmonella enterica serovar Typhimurium infection in the chicken and protective immunty to rechallenge. Infection and Immunity, v. 73, p. 5173-5182, 2005.

WHITANAGE, G.S.; KAISER, P.; WIGLEY, P.; POWERS, C.; MASTROENI, P.; BROOKS, H.; BARROW, P.; MASKELL, D.; McCONELL, I. rapid expression of chemokines and proinflammatory cytokines in newly hatched chickens infected with Salmonella enterica serovar Typhimurium. Infection and Immunity, v. 72, p. 21522159, 2004.

WEIRUP M.; WAHLSTROM, H.; ENGSTROM, B. Experience of a 10-year use of competitive exclusion treatment as part of the Salmonella control programme in Sweden. International Journal of Food Microbiology, v. 15 p. 287-291, 1992. WILLIAMS, R. C.; GIBBONS R. J. Inhibitions of bacterial adherence by secretory immunoglobulin A: a mechanism of antigen disposal. Science, v. 177, p. 697-699, 1972.

YUN, C. H.; LILLEHOJ, H. S.; LILLEHOJ, E. P. Intestinal immune response to coccidiosis. Developmental and Comparative Immunology, v. 24, p. 303-324, 2000.

ZHU, X.Y.; ZHONG, T.; PANDYA, Y.; JOERGER, R.D. 16S rRNA-based analysis of microbiota from the cecum of broiler chickens. Applied and Environmental Microbiology, v, 68, p. 124-137, 2002.

ZINDEL, H. C; BENNETT, M. V. Salmonellae in poultry feeds. Poultry Science,.v. 47, p. 1925-1928, 1968.

ZIPRIN, R. L.; CORRIER, D. E.; HINTON Jr., A.; BEIER, R. C.; SPATES, G. E.; DELOACH, J. R.; ELISSALDE, M. H. Intracloacal Salmonella typhimurium infection of broiler chickens: reduction of colonization with anaerobic organisms and dietary lactose. Avian Diseases, v. 34, p. 749-753, 1990. 


\section{APÊNDICES}


APÊNDICE A - Composição da Ração Inicial e de crescimento utilizada na alimentação das aves. 


\section{Fórmula ração inicial}

Ingrediente

(\%)

Milho

61,400

Farelo de soja $(45,5 \%)$

34,200

Fosfato bicálcico 24/18

2,000

Calcário fino

0,750

Óleo de soja

0,700

Sal comum

0,400

DL Metionina 99\%

0,185

Lisina

0,105

Cloreto de colina $60 \%$

0,080

PX Frango de corte

0,120

Garantías

Proteína min.

$20,0 \%$

EM min.

2950,0 


\section{Fórmula ração crescimento}

Ingrediente

(\%)

Milho

65,200

Farelo de soja $(45,5 \%)$

29,000

Fosfato bicálcico 24/18

1,900

Calcário fino

0,750

Óleo de soja

2,300

Sal comum

0,400

DL Metionina 99\%

0,165

Lisina

0,165

Cloreto de colina $60 \%$

0,050

PX Frango de corte

0,120

Garantías

Proteína min.

$19,0 \%$

EM min.

3100,0 
APÊNDICE B - Culturas bacterianas utilizadas na preparação do probiótico experimental 


\section{CULTURAS BACTERIANAS}

\section{Lactobacilos}

Lactobacillus plantarum amostras $4 \mathrm{e}, 6 \mathrm{~d}$

$10^{12} \mathrm{UFC} / \mathrm{g}$

Lactobacillus murinus amostra $10 \mathrm{~b}$

$10^{11} \mathrm{UFC} / \mathrm{g}$

Lactobacillus delbrueckii subsp. Lactis amostra $3 f$

$10^{10} \mathrm{UFC} / \mathrm{g}$

Lactobacillus reuteri amostra $7 f$

$10^{11} \mathrm{UFC} / \mathrm{g}$

Lactobacillus salivarum amostra 19fb

$10^{12} \mathrm{UFC} / \mathrm{g}$

Lactobacillus casei pseudoplantarum amostras $2 \mathrm{~d}, 2 \mathrm{e}$

$10^{9} \mathrm{UFC} / \mathrm{g}$

Lactobacillus amilophilus amostra 38

$10^{12} \mathrm{UFC} / \mathrm{g}$

Lactobacillus agilis amostra 57 amrs

$10^{11} \mathrm{UFC} / \mathrm{g}$

Lactobacillus virindiens amostra $92^{\mathrm{a}}$

$10^{12} \mathrm{UFC} / \mathrm{g}$

L. delbrueckii subsp. Delbrueckii amostra 3d

$10^{10} \mathrm{UFC} / \mathrm{g}$

L. delbrueckii subsp lactis amostra $3 \mathrm{f}$

$10^{10} \mathrm{UFC} / \mathrm{g}$

L. amylophilus amostra 1e

$10^{12} \mathrm{UFC} / \mathrm{g}$

Culturas individuais em caldo e ágar MRS. Posteriormente foram misturadas cada uma das culturas em uma cultura comum em caldo MRS. 


\section{Bifidobacterias}

Bifidobacterium bifidus

$10^{12} \mathrm{UFC} / \mathrm{g}$

Cultivado em caldo Bifidobacterium (vide Apêndice D).

\section{Enterococos}

Enterococcus faecium

Enterococcus mundtii

Enterococcus faecalis

Enterococcus carseliflavus

Enterococcus gallinarum
$10^{10} \mathrm{UFC} / \mathrm{g}$

$10^{9} \mathrm{UFC} / \mathrm{g}$

$10^{11} \mathrm{UFC} / \mathrm{g}$

$10^{9} \mathrm{UFC} / \mathrm{g}$

$10^{10} \mathrm{UFC} / \mathrm{g}$

Cultivados individualmente em caldo triptosa soja. Posteriormente foram misturadas cada uma das culturas em uma cultura comum em caldo triptosa soja (vide Apêndice D). 
APÊNDICE C - Composição e controles de qualidade do Betaglucano utilizado no experimento 


\section{Betaglucano}

Goldcell - Betaglucano, é obtido a partir da parede cellular de leveduras Saccharomyces cerevisiae resultado em fibra para consume humano. É um pó fino, de cor marrom a bronze escuro. Goldcell Beta Glucano pode ser usado como suplemento alimentar, imunoestimulante ou como agente espessante.

Análise química típica:

Totais de betaglucano

Proteína total $(\mathrm{N} \times 6.25)$

Umidade $\left(105 \pm 2^{\circ} \mathrm{C}\right)$

pH (solução 1\%)

Capacidade de absorção de água

Metais pesados

Posições das ligações

Ligação terminal - glucoe

Ligação $(1,3)$ - glucose

Ligação $(1,6)$ - glucose

Ligação $(1,4)$ - glucose

Ligação $(1,3,4)$ - glucose $\min .85,0 \%$

máx. $4,0 \%$

máx. 10,0\%

$4,0-6,0$

$6,60 \mathrm{~mL} / \mathrm{g}$

$<2$ ppm

$$
\begin{array}{r}
8,0-12,0 \% \\
30,0-34,0 \% \\
11,0-14,0 \% \\
23,0-25,0 \% \\
1,0-2,0 \%
\end{array}
$$


Ligação $(1,2,3)$ - glucose

Ligação $(1,3,6)$ - glucose

$\underline{\text { Control microbiológico }}$

Contagem total em placas UFC/g

Coliformes Totais - NMP/g

Coliformes fecais - NMP/g

Bolores / Leveduras UFC/g

Salmonella / 25g

E. coli / 25g

Staphylococcus aureus / $25 \mathrm{~g}$

Enterobacteriaceae UFC / 25g
$1,5-3,0 \%$

$1,0-2,0 \%$
Máx. 5000

Máx. 5

Ausente

Máx. 50

Ausente

Ausente

Ausente

$<10$ 
APÊNDICE D - Meios de cultura utilizados 


\section{MEIOS DE CULTURA}

\section{Caldo - Ágar MRS}

$\begin{array}{ll}\text { Peptona de caseína } & 10,0\end{array}$

Extrato de carne $\quad 8,0$

Extrato de levedura $\quad 4,0$

$D(+)$ glucose $\quad 20,0$

Fosfato hidrogenado dipotássico $\quad 2,0$

Tween $80 \quad 1,0 \mathrm{~mL}$

Citrato diamônio hidrogenado $\quad 2,0$

Acetato de sódio $\quad 5,0$

Sulfato de magnesio $\quad 0,2$

Sulfato de manganeso $\quad 0,04$

Ágar (somente na preparação e ágar) $\quad$ 15,0

Autoclavar por 15 minutos a $121^{\circ} \mathrm{C}$

$\mathrm{pH} 5,7 \pm 0,2$ 
Infusão cérebro-coração (BHI)

g/L

Infusão de cérebro de bezerro $\quad 12,5$

Infusão e coração de bovino $\quad 5,5$

$\begin{array}{ll}\text { Proteosa peptona } & 10,0\end{array}$

$\begin{array}{ll}\text { Glucose } & 2,0\end{array}$

Cloreto de sódio $\quad 5,0$

$\begin{array}{ll}\text { Fosfato dissódico } & 2,5\end{array}$

Reduzir com cisteína 0,5g/L.

Misturar e autoclavar por 15 minutos a $121^{\circ} \mathrm{C}$ 


\section{Caldo Bifidobacterium}

$\begin{array}{lr} & \mathrm{g} / \mathrm{L} \\ \text { Peptona especial } & 23,0 \\ \text { Cloreto de sódio } & 5,0 \\ \text { Glucose } & 5,0 \\ \text { Amido solúvel } & 1,0 \\ \text { L-Cisteína HCl } & 0,3 \\ \text { Ágar } & 15,0\end{array}$

Adicionar os componentes em água destilada e completar para o volume de um litro. Misturar. Esquentar até ferver. Autoclavar por 15 minutos a $121^{\circ} \mathrm{C}$. 


\section{Caldo Triptosa soja}

g/L

Digerido pancreático de caseína

17,0

Digerido papaico de soja

3,0

Cloreto de sódio

5,0

Fosfato potássico dibásico

2,5

Glucose

2,5

Adicionar os componentes em água destilada e completar para o volume de um litro.

Autoclavar por 15 minutos a $121^{\circ} \mathrm{C}$.

$\mathrm{pH} 7,3 \pm 0,2$ 


\section{Ágar XLT4}

g/L

Peptona de carne

1,6

Extrato de levedura

3,0

L-lisina

5,0

Xilose

3,75

Lactose

7,5

Sucrose

7,5

Citrato de amonio férrico

0,8

Tiosulfato de sódio

6,8

Cloreto de sódio

5,0

Ágar

18,0

Vermelho fenol

0,08

Misturar 59g em 1 litro de água deionizada. Esquentar até ferver e dissolver completamente. Deixar esfriar até $45^{\circ} \mathrm{C}$. Adicionar tergitol $4,6 \mathrm{~mL}$ por cada litro preparado. Misturar e colocar nas placas. Não autoclavar.

$\mathrm{pH} 7,4 \pm 0,2$ 


\section{Água peptonada $0,1 \%$}

$\begin{array}{ll}\text { Peptona } & 1 \mathrm{~g}\end{array}$

Água destilada 1 litro

Diluir e autoclavar x 15 minutos a $121^{\circ} \mathrm{C}$. Deixar esfriar. 
APÊNDICE E - Meio de enriquecimento M199 - Earle 


\section{MEIO 199 (EARLE)}

Mistura de sais enriquecidos com aminoácidos, vitaminas e outros componentes essencias.

Composição

SAIS ORGÂNICOS

$\mathrm{CaCl} 2 \mathrm{H} 2 \mathrm{O}$

$\mathrm{Fe}(\mathrm{NO} 3) 39 \mathrm{H} 2 \mathrm{O}$

$\mathrm{MgSO} 47 \mathrm{H} 2 \mathrm{O}$

$\mathrm{KCL}$

$\mathrm{C} 2 \mathrm{H} 3 \mathrm{O} 2 \mathrm{Na}$

$\mathrm{NaCl}$

$\mathrm{NaHCO} 3$

$\mathrm{NaH} 2 \mathrm{PO} 4 . \mathrm{H} 2 \mathrm{O}$

AMINOÁCIDOS

L-alanina

L-arginina.HCL

L-ácido aspártico

L-cisteína.HCL.H2O

L-cistina

L-ácido glutâmico

L-glutamina

Glicina

L-histidina.HCL.H2O

Hidroxiprolina

L-isoleucina
mg/L

265,00

0,72

200,00

400,00

50,00

$6.800,00$

$2.200,00$

125,00

$\mathrm{mg} / \mathrm{L}$

25,00

70,00

30,00

0,11

26,00

75,00

100,00

50,00

21,88

10,00

20,00 
L-lisina.HCL

70,00

L-fenilalanina

25,00

L-leucina

60,00

L-metionina

15,00

L-prolina

40,00

L-serina

25,00

L-treonina

30,00

L-triptofano

10,00

L-tirosina

57,70

L-valina

25,00

VITAMINAS

$\mathrm{mg} / \mathrm{L}$

Ácido ascórbico

0,050

Biotina

0,010

Calciferol

0,100

Pantotenato de cálcio

0,010

Cloreto de colina

0,500

Ácido fólico

0,010

Inositol

0,050

Menadione

0,010

Ácido nicotinico

0,025

Niacinamida

0,025

Ácido p-aminobenzóico

0,050

Piridoxal.HCL

0,025

Piridoxina.HCL

0,025

Riboflavina

0,010 
Tiamina. $\mathrm{HCl}$

0,010

Acetato de retinol

0,140

Fosfato de tocoferol $\mathrm{Na}$

0.01

OUTROS COMPONENTES

$\mathrm{mg} / \mathrm{L}$

Adenina sulfato

10,00

Adenosina trifosfato $-2 \mathrm{Na}$

1,00

Adenosina monofosfato $-\mathrm{Na}$

0,20

Colesterol

0,20

Deoxiribose

0,50

Glicose

1000.00

Glutathione

0,050

Guanina.HCL

0,30

Hipoxantina

0,30

Vermelho de fenol

20,00

Ribose

0,50

Xantina $\mathrm{Na}$

0.344

Timina

0,30

Tween80

20,00

Uracil

0,30 